\title{
PROTON RESONANCE SPECTROSCOPY
}

\author{
Final Report \\ June, 1996 - May, 2009 \\ J. F. Shriner, Jr. \\ Tennessee Technological University
}

Cookeville, TN 38505

July, 2009

PREPARED FOR THE U. S. DEPARTMENT OF ENERGY

UNDER GRANT NUMBER DE-FG02-96ER40990 


\section{Contents}

$\begin{array}{ll}\text { Preface } & 3\end{array}$

1 Statistical Descriptions of Nuclear Energy Levels $\quad 4$

1.1 A Complete Level Scheme for ${ }^{30} \mathrm{P}$. . . . . . . . . . . . . . . . . . . . . . . . . . . . . 4

1.2 Symmetries and Statistical Properties - Eigenvalues and Reduced Transition Probabilities ............................ 5

1.3 The Thermodynamic Internal Energy $U$ as an Eigenvalue Statistic . . . . . . . . . . 8

1.4 Estimates of Missing and Spurious Level Fractions . . . . . . . . . . . . . . . . . . 10

1.4.1 Estimates of the Number of Missing Levels . . . . . . . . . . . . . . . . . 11

1.4.2 Estimates of the Number of Spurious Levels . . . . . . . . . . . . . . . . . . . 11

1.5 Parity Dependence in Experimental Level Densities . . . . . . . . . . . . . . . . . . 12

2 Nuclear Astrophysics $\quad 14$

2.1 Identification and Characterization of States in ${ }^{19} \mathrm{Ne}$. . . . . . . . . . . . . . . . 14

2.1.1 Interference Effects in the Elastic Scattering of Protons from ${ }^{18} \mathrm{~F}$. . . . . . . 14

2.1.2 Study of Unbound States in ${ }^{19} \mathrm{Ne}$ via the ${ }^{2} \mathrm{H}\left({ }^{18} \mathrm{~F}, \alpha+{ }^{15} \mathrm{O}\right) \mathrm{n}$ Reaction . . . . . 14

2.2 Measurement of the 183-keV Resonance in the ${ }^{17} \mathrm{O}(\mathrm{p}, \alpha)$ Reaction . . . . . . . . . . . 16

2.3 Spectroscopic Study of Low-lying ${ }^{16} \mathrm{~N}$ Levels . . . . . . . . . . . . . . . . . . . . . 17

2.4 Measurement of the ${ }^{17} \mathrm{~F}(\mathrm{p}, \gamma)$ Cross Section near the $E_{c m}=600 \mathrm{keV}$ Resonance . . 17

2.5 Nuclear Structure near ${ }^{132}$ Sn with Transfer Reactions . . . . . . . . . . . . . . . . . 18

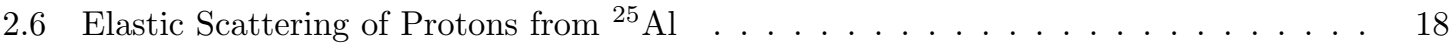

$\begin{array}{lr}\text { References } & 20\end{array}$

$\begin{array}{lr}\text { Appendix II } & 23\end{array}$ 


\section{Preface}

This report summarizes work supported by the DOE Grant DE-FG02-96ER40990 during its duration from June 1996 to May 2009. Topics studied can be grouped into two broad categories. The first category includes statistical descriptions of nuclear levels and measurements of proton resonances relevant to such descriptions. The other category includes measurements at HRIBF relevant to nuclear astrophysics. I express my thanks to colleagues and staff at both TUNL and ORNL for their assistance through the years. 


\section{Statistical Descriptions of Nuclear Energy Levels}

\subsection{A Complete Level Scheme for ${ }^{30} \mathbf{P}$}

Work performed in collaboration with E. G. Bilpuch, M. A. Blackston, C. R. Bybee, J. M. Drake, S. C. Frankle, C. A. Grossmann, M. A. LaBonte, S. J. Lokitz, G. E. Mitchell, E. F. Moore, G. A. Vavrina, P. M. Wallace, and C. R. Westerfeldt

A series of experiments were performed to establish a complete level scheme for ${ }^{30} \mathrm{P}$. Resonances in the ${ }^{29} \mathrm{Si}(\mathrm{p}, \gamma){ }^{30} \mathrm{P}$ reaction were identified by Frankle et al. [1]. A Compton-suppressed $\gamma$-ray spectrometer was designed and built to enable detailed studies of $\gamma$-ray decays [2]. Branching ratios were measured and analyzed for numerous levels $[3,4]$. The final steps were to measure angular distributions of primary and secondary $\gamma$-rays and to compare the experimental level scheme with shell-model calculations of the eigenvalues. The result was a level scheme for ${ }^{30} \mathrm{P}$ up to $E_{x}=8.014 \mathrm{MeV}$ in which most states had unique assignments for spin $J$, parity $\pi$, and isospin $T$ and the remaining states had a most probable assignment [5].

The high quality of these data, believed to be nearly complete and nearly pure, makes a meaningful statistical analysis possible. Nearest-neighbor spacing distributions are shown in Fig. 1 for several different ways of grouping states. We find that the inclusion or neglect of isospin in identifying

$$
{ }^{30} \mathrm{P}
$$
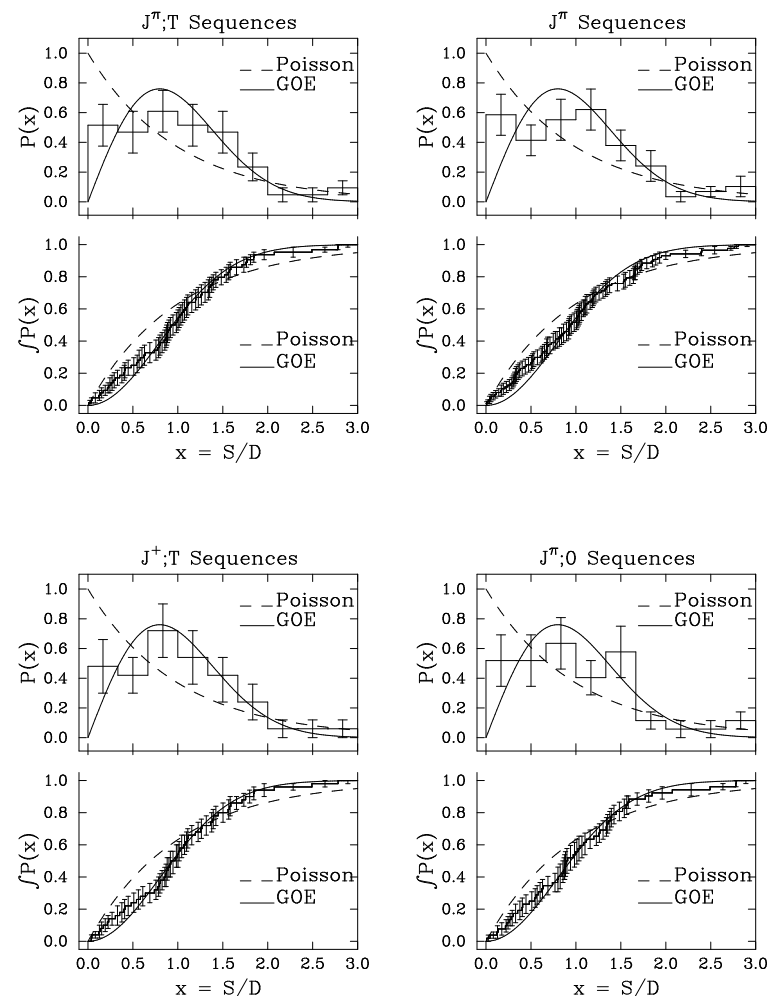

Figure 1: Nearest-neighbor spacing distributions in ${ }^{30} \mathrm{P}$. The titles on each individual figure indicate which quantum numbers were used to identify level sequences.

level sequences has no significant effect on the distributions. This is similar to what was observed in ${ }^{26} \mathrm{Al}[6,7]$ and is consistent with what is expected for a broken symmetry of this magnitude 
$[8,9,10]$. These two measurements of nuclear level schemes have been complemented by studies of classical eigenvalue systems where the experimenter can control the degree of symmetry-breaking $[11,12]$ to show that the current picture of how symmetry-breaking affects eigenvalue statistics is well described by random-matrix theory [13]. Our work on ${ }^{30} \mathrm{P}$ is described in more detail in Ref. [14].

\subsection{Symmetries and Statistical Properties - Eigenvalues and Reduced Transition Probabilities}

Work performed in collaboration with A. A. Adams, B. A. Brown, K. T. Mahar, G. E. Mitchell, and W. E. Ormand

Because the eigenvalue tests of chaos place such stringent requirements on data quality, alternate signatures would be very useful. Alhassid and Feingold [15] suggested that transition strengths of chaotic systems should follow a $\chi^{2}(\nu)$ distribution with $\nu=1$ and that transition strengths of regular systems should follow a $\chi^{2}(\nu)$ distribution with $\nu<1$. Studies of transition strengths calculated within the Interacting Boson Model were in good agreement with this prediction [16]. We set out to apply these concepts to experimental reduced transition probabilities in ${ }^{26} \mathrm{Al}$.

To eliminate possible effects due to sample size or experimental uncertainties, we began with a model system. B(M1) and B(E2) values were calculated for transitions in ${ }^{22} \mathrm{Na}$ using the shellmodel code OXBASH. The distributions of these reduced transition strengths were examined for dependence on spins, multipolarity, isospin character, and excitation energy. We found no significant effects due to any of these factors. The overall distribution was well characterized by a $\chi^{2}(\nu=1)$ distribution [17].

We then turned to using the experimental transition strengths from ${ }^{26} \mathrm{Al}[18,19,20,21]$. Here sample sizes of individual transition sequences (a set of transition sequences with common values for the initial spin, the final spin, the isospin change, and the electromagnetic character) are much smaller, and techniques had to be developed to combine appropriately results from different transition sequences. The results were definitely not in agreement with a $\chi^{2}(\nu=1)$ distribution. In fact, they are not in agreement with a $\chi^{2}$ distribution for any value of $\nu$ [22]. Our first suspicion was that this lack of agreement was due to the effects of experimental limitations on detecting small transition strengths. However, Monte Carlo calculations to test this hypothesis did not reproduce the observed distributions. Subsequent studies of experimental transition strengths in ${ }^{30} \mathrm{P}$ revealed similar behavior [14].

We suggested at the time that this discrepancy might reflect the effects of the broken isospin symmetry on the distribution, and two theoretical studies soon provided further evidence that a broken symmetry could affect these distributions in a qualitatively similar fashion [23, 24]. An experimental measurement of two coupled superconducting microwave cavities provided further evidence of this behavior [25]. To explore this phenomenon in greater detail, we studied such distributions utilizing the nuclear shell model.

We used the shell-model code OXBASH [26] to calculate eigenvalues as well as $B(M 1)$ and $B(E 2)$ values for the nuclides ${ }^{22} \mathrm{Na},{ }^{26} \mathrm{Al}$, and ${ }^{34} \mathrm{Cl}$. In each case, the calculations were performed utilizing both a Hamiltonian that conserved isospin (IC) and a Hamiltonian in which isospin was not a good quantum number (INC); the isospin-breaking calculations followed the method of Ormand and Brown [27]. In the case of the isospin-nonconserving calculations in ${ }^{26} \mathrm{Al}$, two different sets of single-particle energies were utilized, one based on the $A=39$ system (hereafter labeled $\mathrm{INC}_{A}$ ) and one based on the $A=17$ system $\left(\mathrm{INC}_{B}\right)$. Both eigenvalue distributions and reduced transition probability distributions have been analyzed. First we examined eigenvalue distributions.

The methods applied to determine eigenvalue distributions have been outlined in Ref. [28]. Expectations are that when all quantum numbers are good ones, the distributions will follow those obtained from the Gaussian orthogonal ensemble (GOE) version of random matrix theory [13]. The 
effects of a broken symmetry have been described by Dyson [8] and Pandey [9]; one expects a transition (potentially a very rapid one) from no effects at all when the symmetry is good through a regime where the eigenvalue distributions are distorted because of the broken symmetry to a point where the distributions show no remnants of the symmetry even though the symmetry may still be relatively good from the perspective of other measures. The rapid changes in the distribution as the degree to which the symmetry is broken varies make the study of such distributions a potentially sensitive tool.

The eigenvalue results for ${ }^{26} \mathrm{Al}$ are illustrated in Fig. 2, where we show nearest-neighbor spacing distributions (NNSD's). We note that the $\mathrm{INC}_{A}$ NNSD's show essentially no difference from the

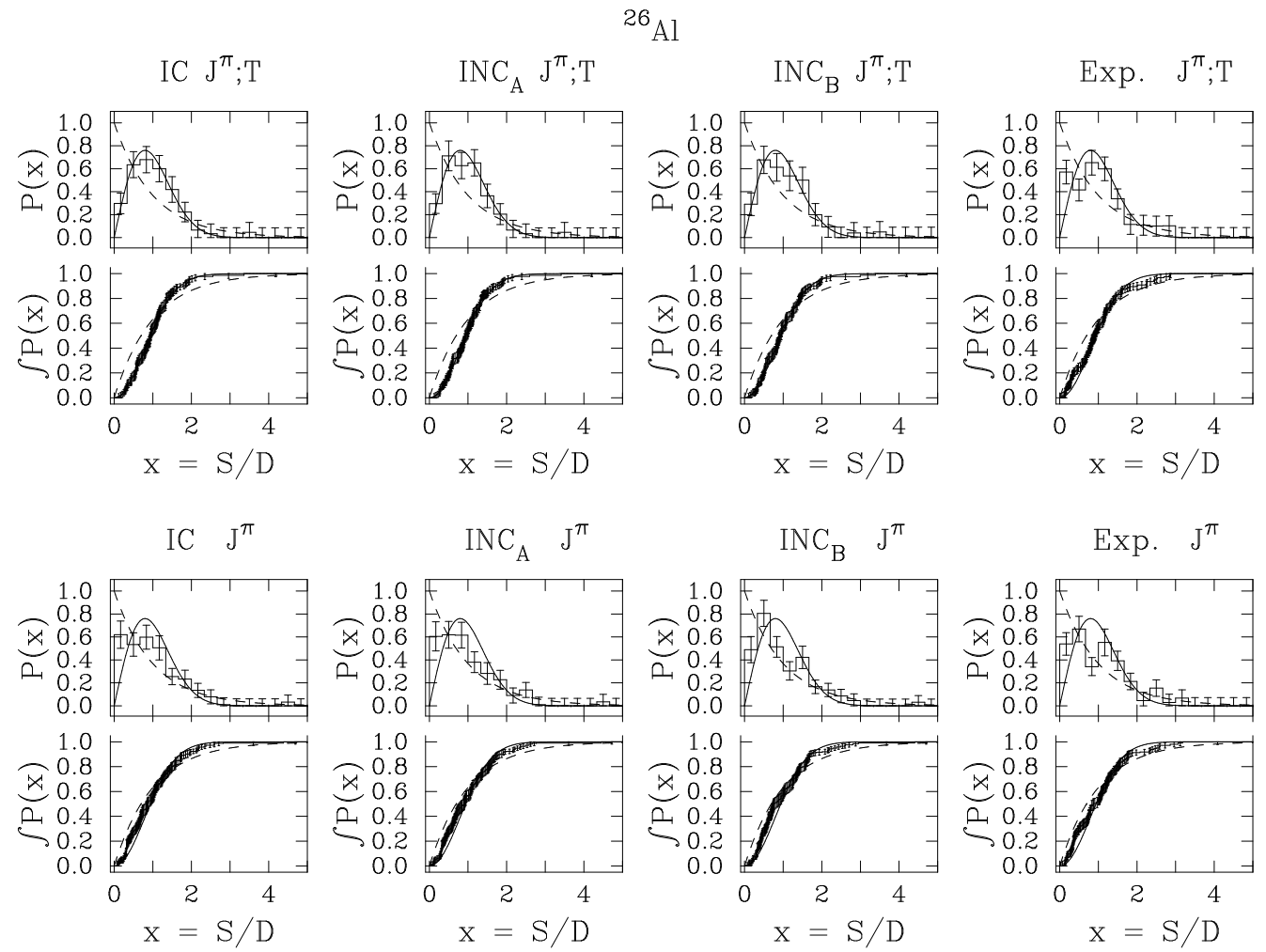

Figure 2: Nearest-neighbor spacing distributions for shell-model and experimental eigenvalues in ${ }^{26} \mathrm{Al}$. The labels on each graph indicate which quantum numbers were used to identify the sequences during analysis. Solid curves show GOE distributions, while dashed curves show Poisson distributions.

calculations with isospin conserved. The $\mathrm{INC}_{B}$ calculations do differ from GOE, although not quite to the extent that the experimental data do. The reason for the differences in the two shellmodel calculations is that the Coulomb matrix element (and hence the degree of isospin breaking) is approximately four times larger for $\mathrm{INC}_{B}$. The reason why the experimental data showed even larger deviations than the $\mathrm{INC}_{B}$ calculation is not well understood. These results were published in Ref. [29].

Fig. 3 shows the transition distributions for the IC and $\mathrm{INC}_{B}$ calculations for ${ }^{26} \mathrm{Al}$. Here we see that the $\mathrm{INC}_{B}$ Hamiltonian produces noticeable changes in some of the distributions. The $\mathrm{INC}_{A}$ calculation shows qualitatively similar results, although the changes from the IC calculation are less pronounced.

One important result of this analysis was the clear indication that, unlike the situation for the 


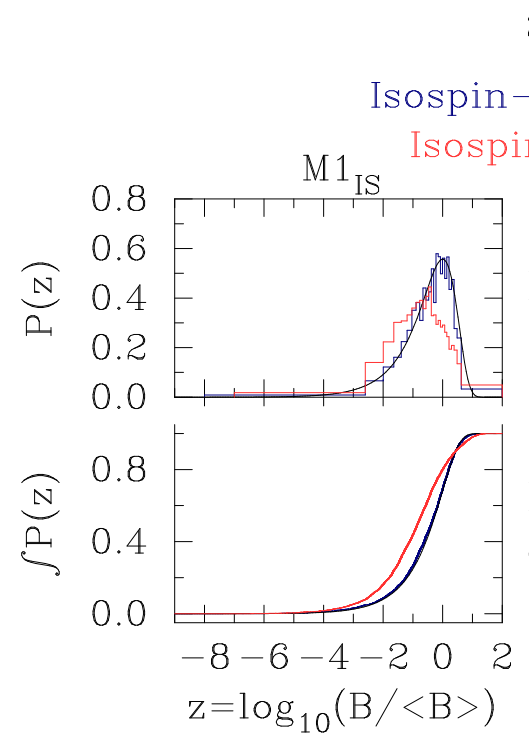

${ }^{26} \mathrm{Al}$

nserving
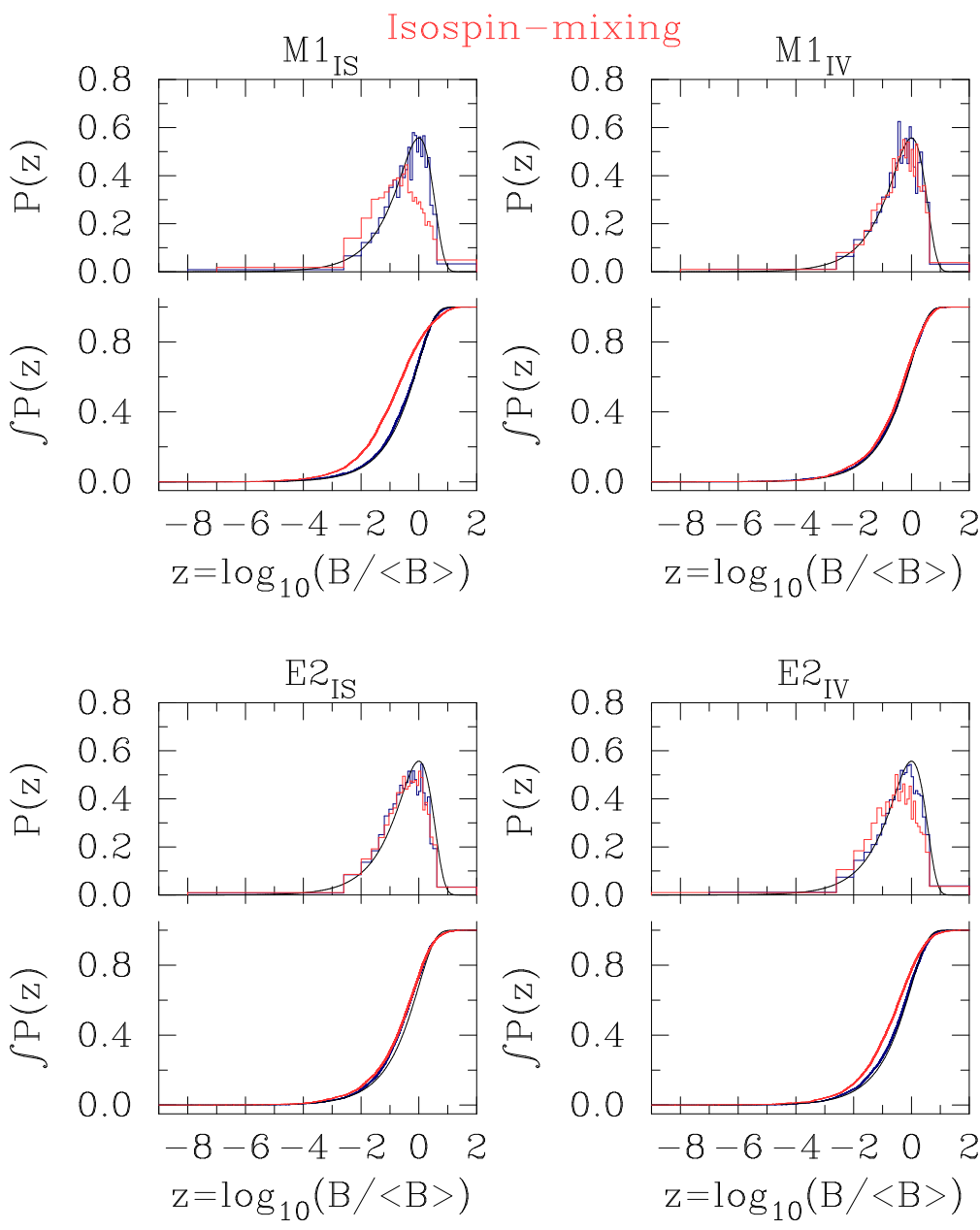

Figure 3: Distributions of reduced transition probabilities for the IC (in red) and $\mathrm{INC}_{B}$ (in blue) calculations in ${ }^{26} \mathrm{Al}$. The smooth black curves show the Porter-Thomas distribution.

eigenvalue distributions, the effect of a broken symmetry on transition distributions is not a generic effect - it depends on the specific group of transitions under consideration. In the cases we considered here, $M 1$ isoscalar transitions are affected more than $M 1$ isovector transitions, whereas $E 2$ isovector transitions are affected more than $E 2$ isoscalar transitions. In each case, $M 1$ and $E 2$, the transitions whose distribution is affected more by isospin mixing is the one which is inherently weaker, as can be seen in Table 1. Although the transition distributions appear to be very sensitive to the effects of symmetry breaking, the fact that dynamics also plays a role will make it more difficult to utilize this method as a tool to quantify the degree of symmetry breaking. A paper describing these results was published in Phys. Rev. C [30]. 
Table 1: Summary of shell-model transition calculations in ${ }^{26} \mathrm{Al} . N$ is the number of transitions in the sequence.

\begin{tabular}{|c|c|c|c|c|c|c|c|c|}
\hline Hamiltonian & \multicolumn{2}{|c|}{$M 1_{I S}$} & \multicolumn{2}{|c|}{$M 1_{I V}$} & \multicolumn{2}{|c|}{$E 2_{I S}$} & \multicolumn{2}{|c|}{$E 2_{I V}$} \\
\hline & $N$ & $\begin{array}{c}B(M 1)_{a v g} \\
\quad(\text { W.u. })\end{array}$ & $N$ & $\begin{array}{c}B(M 1)_{\text {avg }} \\
(\text { W.u. })\end{array}$ & $N$ & $\begin{array}{c}\text { B(E2) avg } \\
\quad(\text { W.u. })\end{array}$ & $N$ & $\begin{array}{c}B(E 2)_{\text {avg }} \\
\quad(\text { W.u. })\end{array}$ \\
\hline $\mathrm{IC}$ & 2464 & 0.00027 & 1918 & 0.11 & 3653 & 2.9 & 2696 & 0.073 \\
\hline $\mathrm{INC}_{A}$ & 2464 & 0.0032 & 1919 & 0.11 & 3654 & 2.8 & 2697 & 0.19 \\
\hline $\mathrm{INC}_{B}$ & 2561 & 0.013 & 1900 & 0.096 & 3756 & 2.5 & 2708 & 0.53 \\
\hline
\end{tabular}

\subsection{The Thermodynamic Internal Energy $U$ as an Eigenvalue Statistic}

\section{Work performed in collaboration with G. E. Mitchell, M. P. Pato, and A. P. B. Tufaile}

In some of the early development of random matrix theory (RMT), Dyson [31, 32, 33] began to relate thermodynamic concepts to spectra from the various random matrix ensembles. Little was done with this idea for 40 years. The challenge in comparing experimental energy spectra with the predictions of RMT has always been the need for pure and complete spectra. Missing or spurious levels can strongly affect almost all the eigenvalue statistics that have been studied. As discussed below, such statistics can even be used in some cases to estimate the fraction of missing levels [34]. We have explored how the thermodynamic "internal energy" per particle, $U$, behaves for complete spectra and when missing or spurious levels affect the spectra.

Consider a spectrum of $N$ energy eigenvalues $E_{i}$ such that (1) the average level spacing is constant and equal to one in an appropriate set of units and (2) the energies are centered on a range of $[-L, L]$, where $L=N / 2$. (If these are not satisfied, renormalize the energies so that these conditions are met.) Then the appropriate formula for $U$ is

$$
N U=-\sum_{j>i} \ln \left|\frac{E_{j}-E_{i}}{j-i}\right|+\sum_{i}\left[V\left(E_{i}\right)-V\left(\xi_{i}\right)\right] .
$$

Here $V$ is a potential energy given by

$$
V(E)=(L-E) *\left[\frac{1}{2}+\ln \left(\frac{L-E}{2 L}\right)\right]+(L+E) *\left[\frac{1}{2}+\ln \left(\frac{L+E}{2 L}\right)\right],
$$

and the $\xi_{i}$ are the eigenvalues of a "picket fence" spectrum:

$$
\xi_{i}=-L+i-\frac{1}{2}
$$

For a Gaussian orthogonal ensemble (GOE) spectrum, the expected value of $U$ is 0.365 ; for a Poisson spectrum,

$$
<U>_{\text {Poisson }}=\sum_{i=1}^{N}\left[(N-i) \ln i-V\left(\xi_{i}\right)\right]-\frac{1}{4} N(N-1)(2 \ln N-3) \approx 0.499 \ln N+0.174 .
$$

Our emphasis was on applications of this statistic to an individual spectrum, the type of application that might be relevant for a set of experimental data. We randomly generated ensembles of spectra, both GOE and Poisson, of various sizes. For pure and complete spectra, the median values behaved as shown in Fig. 4. For spectra with $N$ larger than $\approx 30-40$, we observed very good separation between the GOE and Poisson cases. For the smaller spectra, the problem was (as it seems to be with almost all eigenvalue statistics) that the Poisson spectra have such large standard 


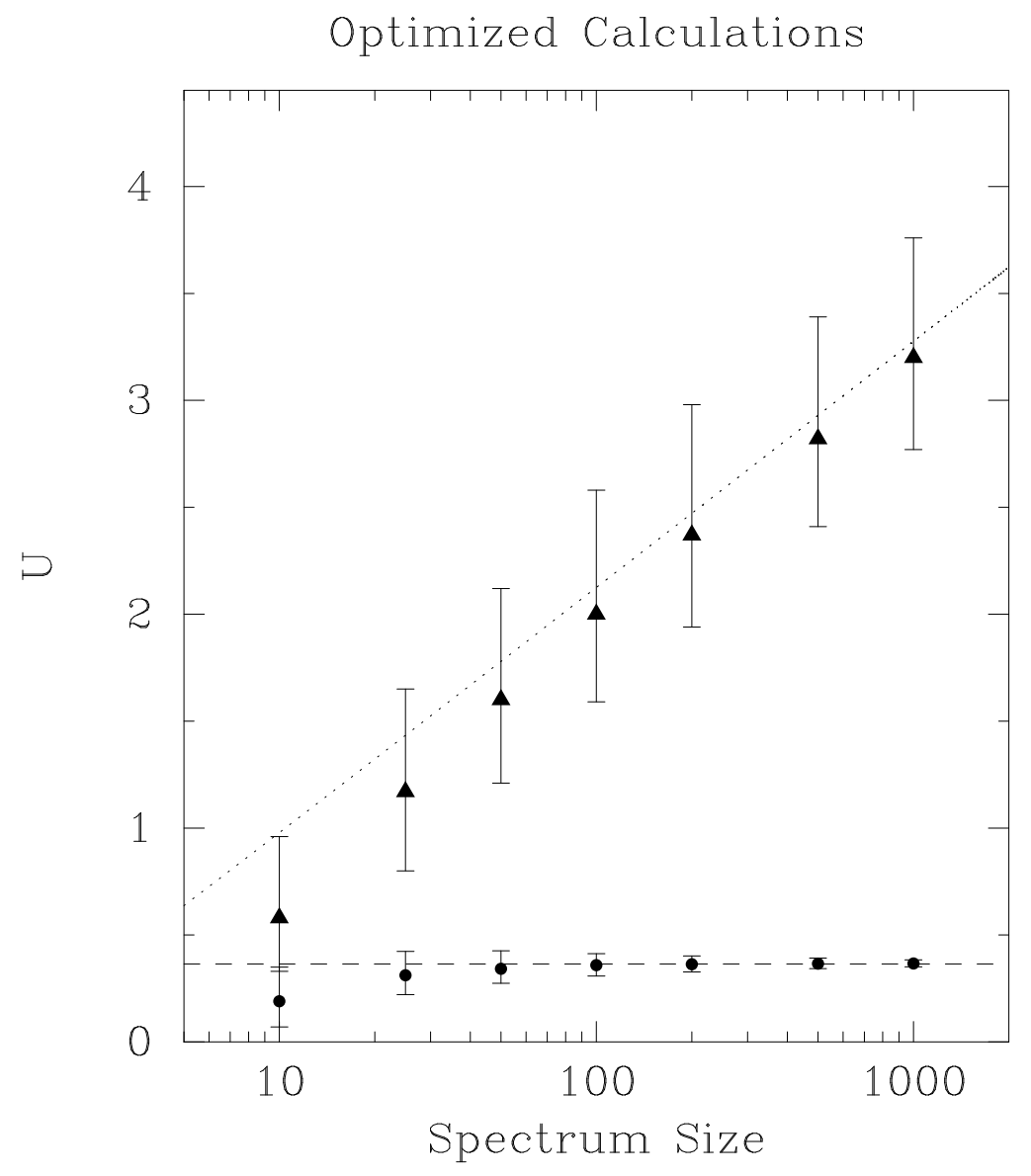

Figure 4: Behavior of the internal energy $U$ as a function of spectrum size; median values are indicated for GOE spectra with circles and for Poisson spectra with triangles. The dashed and dotted lines show the expected values for GOE and Poisson spectra, respectively.

deviations that any individual spectrum is likely to fall well within the range obtained for GOE spectra of that size.

When one has missing or spurious levels in GOE spectra, the effect is that the values of $U$ begin to move toward their Poisson values. How quickly that change occurs and how much spread it introduces over the members of the ensemble determine how effective any statistic can be at still identifying the underlying spectrum as GOE. With sufficient sensitivity, one may even be able to use the statistic to estimate the fraction of missing or spurious levels. A summary of our results for this question is presented in Fig. 5 and compared to the behavior of the $\Delta_{3}$ statistic for the same spectra. The figure shows that while the expected values of $\Delta_{3}$ deviate from the expected values more quickly as levels are missed or mistakenly included, the standard deviation of $\Delta_{3}$ also increases more rapidly. In that sense, $U$ appears to be at least as good as $\Delta_{3}$ as a tool for characterizing spectra. A manuscript providing more details of these simulations has been published in Nuclear Instruments and Methods [35]. 


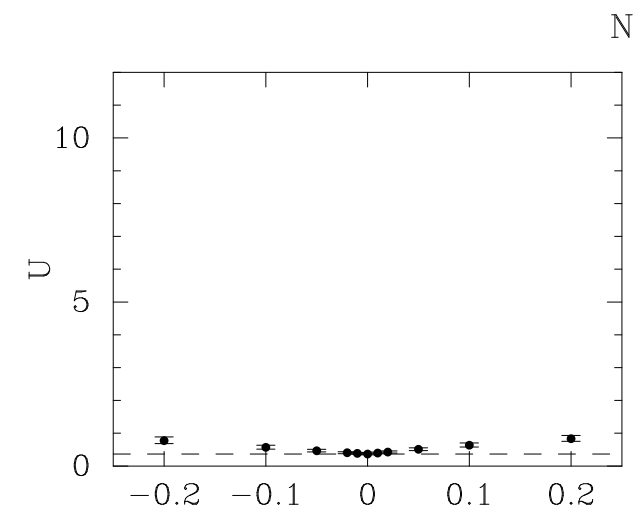

$\mathrm{N}=500$
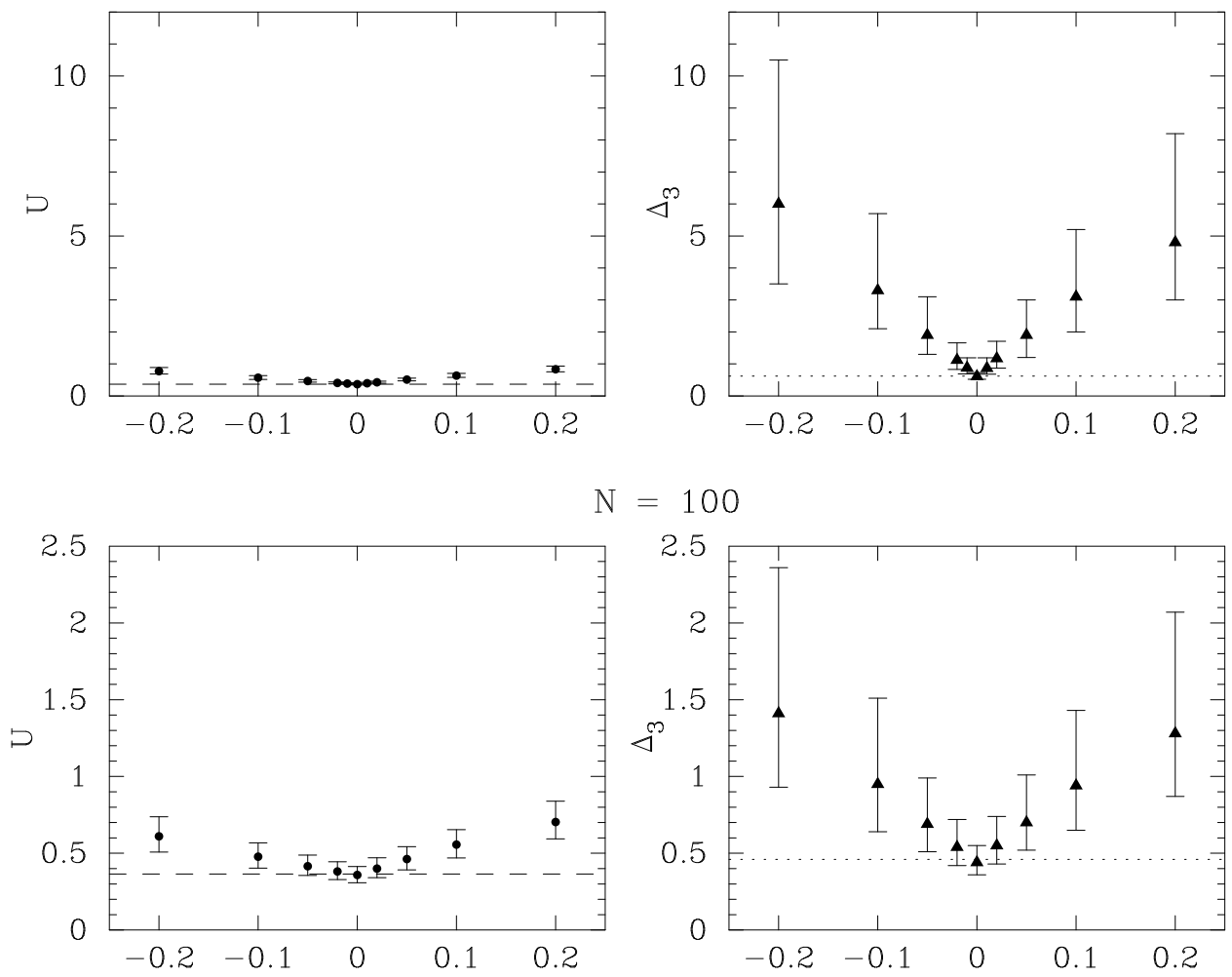

$\mathrm{N}=100$
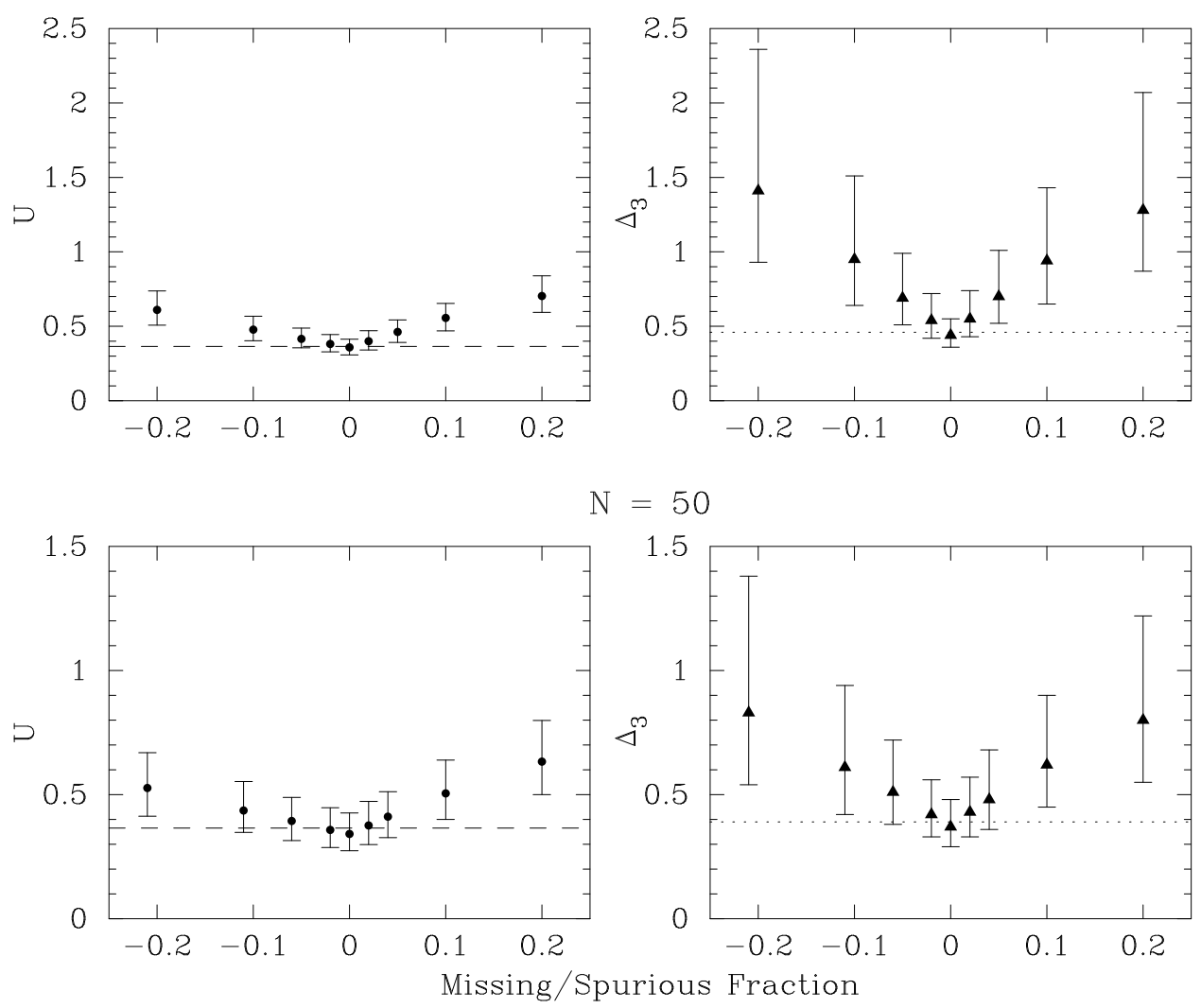

Figure 5: $U$ (circles) and $\Delta_{3}$ (triangles) as a function of missing/spurious fraction. $\Delta_{3}$ has been calculated for the full spectrum. The dashed line indicates the expected value of $U$ for GOE spectra, while the dotted line indicates the expected values of $\Delta_{3}$ for GOE spectra.

\subsection{Estimates of Missing and Spurious Level Fractions}

Work performed in collaboration with U. Agvaanluvsaan, G. E. Mitchell, P. D. O'Malley, M. P. Pato, and R. C. Roller

Statistical evaluations of resonance data play an important role both in understanding the data and in evaluating the quality of the data. As previously discussed, there are tests, some involving 
eigenvalues and others involving transition probabilities, that have been utilized along one or the other of these lines, but each of them has its own set of limitations. We developed and published a new method of estimating how many levels have been missed in a sequence and have begun exploration of two new approaches in this realm.

\subsubsection{Estimates of the Number of Missing Levels}

One of the concerns in statistical analyses is the quality of the data, since a number of the standard measures require very high quality data with few missing levels and few misassigned levels. Other times, such as when determining level densities, one may just wish an estimate of the number of missing or spurious levels.

Traditionally, estimates of missing levels have been made by comparing reduced width distributions to the expected Porter-Thomas distribution [36]. Experimentally, levels with sufficiently small reduced widths are likely to be unobserved, and comparison of the measured and expected distributions allows an estimate of the missing fraction.

We developed a method that utilizes the eigenvalues rather than the reduced widths. A distribution for nearest-neighbor spacings that includes the effects of missing levels was derived. Since spacings and widths are uncorrelated, this provides a second, independent estimate of the fraction of missing levels. The combination of two methods generally produces better methods than the width distribution by itself did.

Details of this method have been published in a Nuclear Instruments and Methods paper [34], and applications of the method to experimental proton data have been given in a second paper [37]. The development and application of the method was the subject of the Ph.D. thesis of U. Agvaanluvsan.

Recently, we have begun to look at how other statistical measures could be used in a similar fashion to estimate the number of missing levels in a sequence. Simulated spectra have been analysed using the Dyson-Mehta $\Delta_{3}$ statistic [38], the thermodynamic energy $U$ [33], the statistic $Q$ (also introduced by Dyson and Mehta) [38], and the linear correlation coefficient between adjacent spacings. A program is being written to use each of the 5 measures discussed here to estimate the number of missing levels.

\subsubsection{Estimates of the Number of Spurious Levels}

In addition to desiring to estimate how many levels may have been missed in a sequence, one also would like an estimate of how many levels may have been included in the sequence mistakenly due to misassignment of one or more quantum numbers. How to estimate the fraction of these "spurious" levels is much less clear than how to deal with missing levels. We have investigated whether the spacing distribution could also be utilized to estimate the number of spurious levels in a data set.

Our approach relied on the fact that the spacing distribution for a superposition of GOE spectra is known [39]. We define the spacings between adjacent levels to be $S_{i}$, the average spacing to be $D$, and the normalized spacings to be $x_{i} \equiv S_{i} / D$. In the simplest case where $n$ spectra are superimposed with relative probabilities $f_{i}\left(\sum f_{i}=1\right)$, then the spacing distribution is

$$
\begin{aligned}
P(x) & =E(x)\left\{\sum_{i} f_{i}^{2} \frac{p_{i}\left(f_{i} x\right)}{E_{i}\left(f_{i} x\right)}+\left[\sum_{i} f_{i} \frac{1-\Psi_{i}\left(f_{i} x\right)}{E_{i}\left(f_{i} x\right)}\right]^{2}-\sum_{i}\left(f_{i} \frac{1-\Psi_{i}\left(f_{i} x\right)}{E_{i}\left(f_{i} x\right)}\right)^{2}\right\} \\
p(x) & =\frac{\pi}{2} x \exp \left(-\frac{\pi}{4} x^{2}\right) \\
E(x) & =1-\frac{2}{\sqrt{\pi}} \int_{0}^{x \sqrt{\pi} / 2} e^{-y^{2}} d y \\
\Psi(x) & =1-\exp \left(-\frac{\pi}{4} x^{2}\right) .
\end{aligned}
$$


For the case $n=2$, we can express our result in terms of a single probability $f$ which represents the probability that a level is from the smaller sequence (hence $f \leq 0.5$ ). This reduces to a relatively simple result for $x=0$ :

$$
P(0)=2 f(1-f) .
$$

Our initial goal was to see if we could determine $P(0)$ with sufficient precision from a sequence of energy eigenvalues to extract a useful value of $f$ from that sequence.

To do this, we utilized GOE spectra of various sizes and with various missing or spurious fractions (as was done in the studies of internal energy described in Sect. 1.3). We focused on the probability density function $\int P(x) d x$, since it is unambiguous for a single spectrum. We first tried an empirical approach, fitting the probability density function with a quadratic function in the region $0 \leq x \leq 0.3$. That proved unreliable because the extracted values of $P(0)$ showed too much variation. Changing the region of $x$ over which we fit did not improve the situation.

Next, we moved to a significantly more complicated procedure, implementing a fit to Eq. (5) over various ranges of small $x$ values. The complications arose because we now had to utilize a nonlinear fitting procedure that at the same time allowed us to put bounds $(0 \leq f \leq 0.5)$ on the possible values of $f$. Although we were able to successfully obtain fitted values of $f$, we once again found that there was too large a variance for those values to make this method practical for application to a single experimental spectrum.

One approach that could be utilized and would probably reduce this variance is to fit the probability distribution function over a larger range of $x$. However, we have not yet pursued this approach. The advantage of restricting the fit to small ranges of $x$ is that the spacing distributions at smaller values are relatively insensitive to the presence of missing levels (our results did verify this behavior). Since an experimental spectrum is likely to include both missing levels and spurious levels at the same time, one ideally would like techniques that are sensitive to only one or the other. Expanding our fitting range to larger values of $x$ would certainly lose that sensitivity at some point. Whether we have reached that point yet remains to be seen. Similarly, the current technique [34] for estimating the fraction of missing levels has not yet been tested to see how it is affected by the presence of spurious levels. These are questions to be pursued in the future.

\subsection{Parity Dependence in Experimental Level Densities}

Work performed in collaboration with W. C. Beal, L. K. McLean, G. E. Mitchell, and S. J. Lokitz

In an attempt to better determine level densities and to provide data suitable for testing the parity dependence of level densities, we measured elastic and inelastic scattering for the $\mathrm{p}+{ }^{44} \mathrm{Ca}, \mathrm{p}+{ }^{50} \mathrm{Cr}$, and $\mathrm{p}+{ }^{52} \mathrm{Cr}$ systems at the TUNL High Resolution Laboratory. Energy ranges and numbers of resonances observed in each case are summarized in Table 2. The numbers show that the observed

Table 2: Summary of resonance measurements.

\begin{tabular}{cccc}
\hline System & $\begin{array}{c}E_{p} \\
(\mathrm{MeV})\end{array}$ & $\begin{array}{c}E_{x} \\
(\mathrm{MeV})\end{array}$ & Number of Resonances \\
\hline $\mathrm{p}+{ }^{44} \mathrm{Ca}$ & $2.50-3.53$ & $9.33-10.34$ & 809 \\
$\mathrm{p}+{ }^{50} \mathrm{Cr}$ & $1.80-3.50$ & $7.04-8.70$ & 185 \\
$\mathrm{p}+{ }^{52} \mathrm{Cr}$ & $2.10-3.47$ & $8.62-9.96$ & 263 \\
\hline
\end{tabular}

level density is approximately 4 times higher in ${ }^{45} \mathrm{Sc}$ than in ${ }^{53} \mathrm{Mn}$, which in turn has a level density approximately twice that of ${ }^{51} \mathrm{Mn}$ in the energy ranges measured. The data and R-matrix fits for the ${ }^{44} \mathrm{Ca}\left(\mathrm{p}, \mathrm{p}_{0}\right)$ and ${ }^{44} \mathrm{Ca}\left(\mathrm{p}, \mathrm{p}_{1}\right)$ reactions at $165^{\circ}$ for the energy range $E_{p}=3.3-3.4 \mathrm{MeV}$ are illustrated in Fig. 6. 

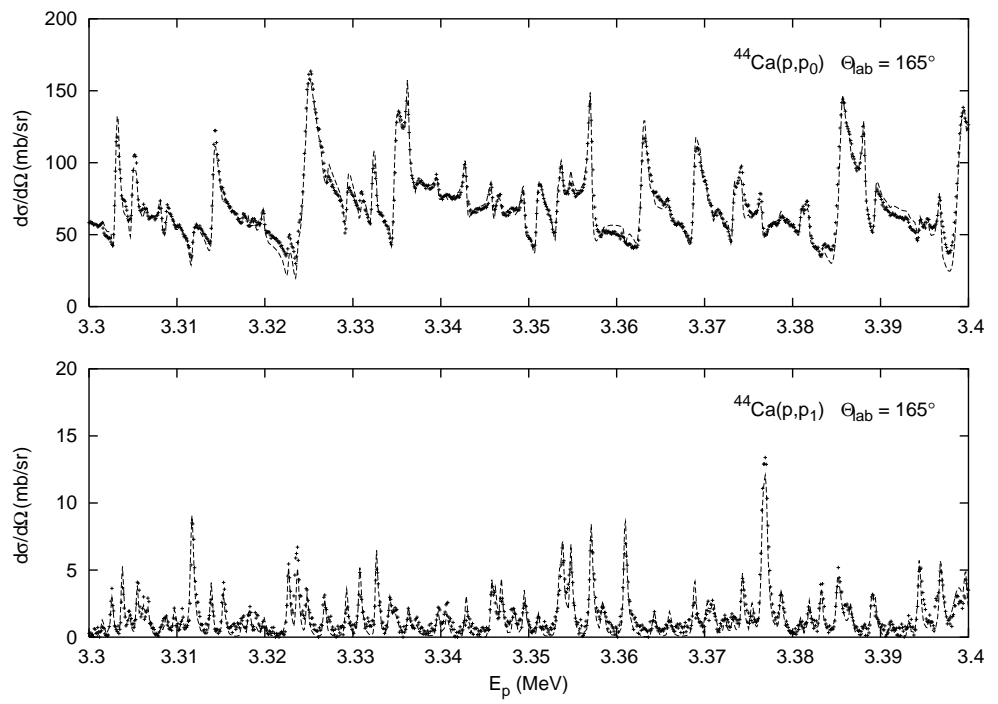

Figure 6: Data and R-matrix fits for the ${ }^{44} \mathrm{Ca}\left(\mathrm{p}, \mathrm{p}_{0}\right)$ and ${ }^{44} \mathrm{Ca}\left(\mathrm{p}, \mathrm{p}_{1}\right)$ reactions at $165^{\circ}$ for the energy range $E_{p}=3.3-3.4 \mathrm{MeV}$.

In each reaction, the quality of each data sequence (levels with the same $J^{\pi}$ values) has been carefully analyzed, and the number of missing levels has been estimated using the procedures outlined in [34]. The $J^{\pi}=1 / 2^{+}$sequences are almost always the best in this regard since identification of the resonance as $\ell=0$ uniquely determines the value of $J$ in these cases. On the other hand, it can be difficult to definitively assign $J$ for $\ell=1$ and $\ell=2$ levels, although inelastic scattering is often helpful, especially for the $\ell=1$ levels. We define an asymmetry $\alpha$ to compare the level densities for $J^{\pi}=1 / 2^{+}$and $J^{\pi}=1 / 2^{-}$to see if there is any evidence of a parity dependence of the level density at these energies:

$$
\alpha=\frac{\rho_{1 / 2^{+}}-\rho_{1 / 2^{-}}}{\rho_{1 / 2^{+}}+\rho_{1 / 2^{-}}} .
$$

Results for each of these three systems are listed in Table 3; no conclusive evidence for a parity dependence of the level densities is observed.

Table 3: Values of $\alpha$ for three compound nuclear systems.

\begin{tabular}{cc}
\hline Nuclide & $\alpha$ \\
\hline${ }^{45} \mathrm{Sc}$ & $-0.02 \pm 0.04$ \\
${ }^{51} \mathrm{Mn}$ & $-0.14_{-0.06}^{+0.11}$ \\
${ }^{53} \mathrm{Mn}$ & $0.06 \pm 0.07$ \\
\hline
\end{tabular}

This work comprised the Ph.D. research of S. J. Lokitz ( $\left.p+{ }^{44} \mathrm{Ca}\right)$, W. C. Beal $\left(p+{ }^{50} \mathrm{Cr}\right)$, and L. K. McLean $\left(p+{ }^{52} \mathrm{Cr}\right)$. Two papers describing the results in ${ }^{45} \mathrm{Sc}$ have been published $[40,41]$. 


\section{$2 \quad$ Nuclear Astrophysics}

\subsection{Identification and Characterization of States in ${ }^{19} \mathrm{Ne}$}

Understanding proton-induced reactions on ${ }^{18} \mathrm{~F}$ is important for understanding not only the production of ${ }^{18} \mathrm{~F}$ in novae $[42,43]$ but also the production and destruction of a number of other nuclides in this mass region. Experiments in recent years by both the HRIBF nuclear astrophysics group and other groups have studied the proton induced resonance reactions into the compound nucleus ${ }^{19} \mathrm{Ne}$ directly $[44,45]$ and also analog states in the mirror nuclide ${ }^{19} \mathrm{~F}$ via the $(\mathrm{d}, \mathrm{p})$ transfer reaction $[46,47]$. Nonetheless, a number of states in ${ }^{19} \mathrm{Ne}$ have not yet been completely characterized, and in fact comparison with the analog nuclide ${ }^{19} \mathrm{~F}$ suggests that a number of states have yet to be identified. A particularly notable uncertainty concerns the role of resonances at center-of-mass energies of 8 and $38 \mathrm{keV}$. These were believed to be $3 / 2^{+}$states, and their role were thought to be crucial to understanding these reaction rates at low energies [48]. As we discuss below, it now appears that at least one of these identifications was incorrect.

\subsubsection{Interference Effects in the Elastic Scattering of Protons from ${ }^{18} \mathbf{F}$}

Work performed in collaboration with K. Y. Chae, D. W. Bardayan, J. C. Blackmon, D. Gregory, M. W. Guidry, M. S. Johnson, R. L. Kozub, R. J. Livesay, Z. Ma, C. D. Nesaraja, S. D. Pain, S. Paulauskas, M. Porter-Peden, M. S. Smith, N. Smith, and J. S. Thomas

De Séréville et al. [49] have emphasized the fact that the relative signs between widths can affect the cross-section of the ${ }^{18} \mathrm{~F}(\mathrm{p}, \alpha)$ reaction by large factors. Measurement of an excitation function for this reaction in the energy range $E_{c m}=663-877 \mathrm{keV}$ has been made at HRIBF using a ${ }^{18} \mathrm{~F}$ beam and the SIDAR detector array [44] covering an angular range of $\theta_{c m}=56^{\circ}-138^{\circ}$. These measurements have allowed us to restrict relative signs among the $3 / 2^{+}$states at center-of-mass energies of 8,38 , and $665 \mathrm{keV}$. Because there are three states that affect the cross-section, there are eight different combinations of signs for the three entrance channel reduced width amplitudes (positive or negative for each of the three states). The data points are illustrated in Fig. 7, along with one combination of signs that is consistent with these data points and one combination that is not.

Four of the eight possible sign combinations (those with a positive reduced width amplitude for the $E_{c m}=665 \mathrm{keV}$ state) are found to be compatible with these measurements, as shown in Fig. 8 . These measurements provide the first experimental constraints on these relative signs. Additional cross-section measurements in the energy range $E_{c m}=330-665 \mathrm{keV}$ are planned to try to restrict the possible combinations even further.

This work was part of the Ph.D. dissertation of K. Y. Chae of the University of Tennessee. It has been published in Phys. Rev. C [50].

\subsubsection{Study of Unbound States in ${ }^{19} \mathrm{Ne}$ via the ${ }^{2} \mathbf{H}\left({ }^{18} \mathbf{F}, \alpha+{ }^{15} \mathrm{O}\right) \mathbf{n}$ Reaction}

Work performed in collaboration with A. S. Adekola, D. W. Bardayan, J. C. Blackmon, C. R. Brune, K. Y. Chae, A. E. Champagne, C. Domizioli, U. Greife, Z. Heinen, M. Hornish, M. S. Johnson, K. L. Jones, R. L. Kozub, R. J. Livesay, Z. Ma, T. N. Massey, B. H. Moazen, C. D. Nesaraja, S. D. Pain, M. Porter-Peden, M. S. Smith, J. S. Thomas, D. W. Visser, and A. Voinov

Two low-lying $3 / 2^{+}$states in ${ }^{19} \mathrm{Ne}$ are expected based on the structure in the mirror nucleus ${ }^{19} \mathrm{~F}$. These states are expected to play an important role in the $\mathrm{p}+18 \mathrm{~F}$ reactions and had been tentatively identified as states that were slightly above the proton separation energy in ${ }^{19} \mathrm{Ne}$. However, definitive identification of these two states has proven difficult. The use of $(d, p)$ reactions to study the analog 


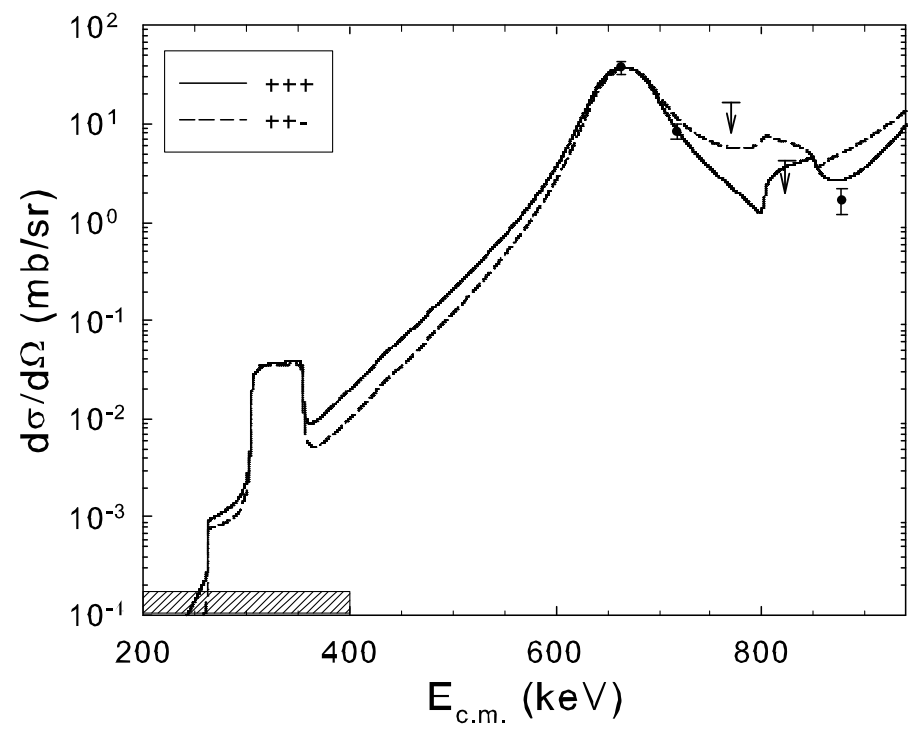

Figure 7: Cross-sections for the ${ }^{18} \mathrm{~F}(\mathrm{p}, \alpha)$ reaction in the range $E_{c m}=663-877 \mathrm{keV}$, along with fits obtained for two different combinations of signs of entrance channel reduced width amplitudes for the 8-, 38-, and 665-keV resonances. The theoretical curves reflect averaging over energy loss in the target and over the angular range $\theta_{c m}=56^{\circ}-138^{\circ}$ covered in these measurements.

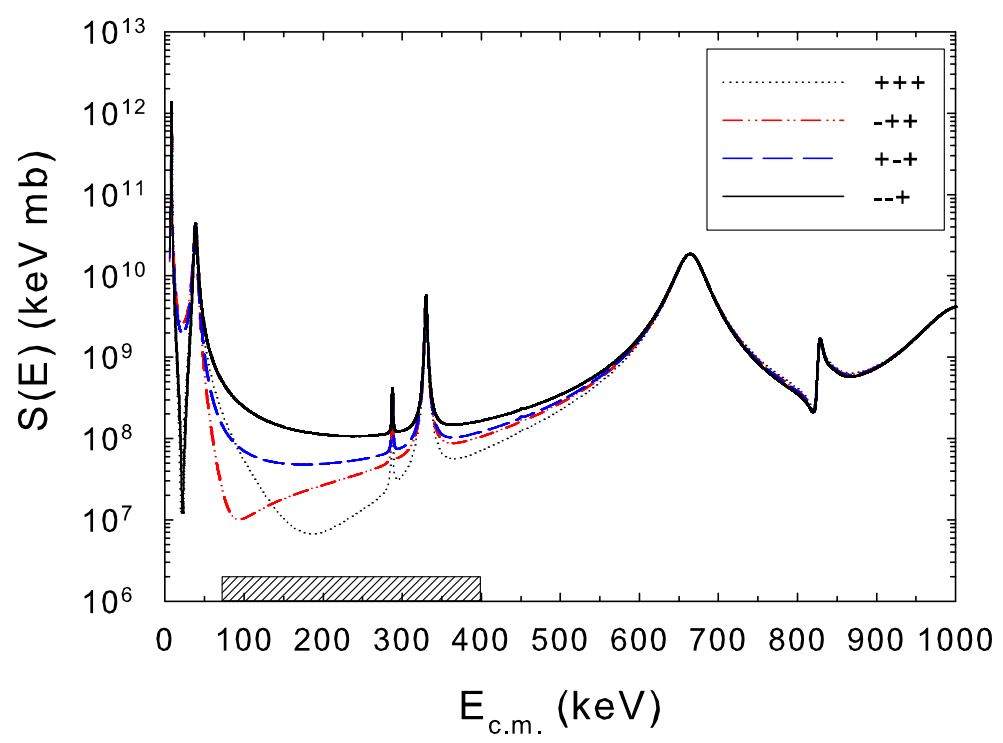

Figure 8: S-factors for the ${ }^{18} \mathrm{~F}(\mathrm{p}, \alpha)$ reaction for the four allowed sign possibilities. 
states in ${ }^{19} \mathrm{~F}$ did not resolve the situation [47, 49]. Population of the two states directly with a proton transfer reaction on ${ }^{18} \mathrm{~F}$ should improve the situation, but the issues involved in neutron detection mean that simply using the $(\mathrm{d}, \mathrm{n})$ reaction is itself problematic. However, for the ${ }^{18} \mathrm{~F}(\mathrm{~d}, \mathrm{n}){ }^{19} \mathrm{Ne}$ reaction, the ${ }^{19} \mathrm{Ne}$ subsequently decays to an $\alpha$ particle and an ${ }^{15} \mathrm{O}$ nucleus, and detection of both of these charged particles in principle allows reconstruction of the energy and angle of the neutrons.

The experiment was run in June-July 2005. A $150-\mathrm{MeV}^{18} \mathrm{~F}^{9+}$ beam was used to bombard a $716-\mu \mathrm{g} / \mathrm{cm}^{2} \mathrm{CD}_{2}$ target. A total of six position-sensitive silicon strip detectors were used, two close to $0^{\circ}$ to detect the ${ }^{15} \mathrm{O}$ nuclei and four at larger angles to detect the $\alpha$ particles. The detector arrangement and reaction kinematics also allowed simultaneous detection of the $\alpha$ and ${ }^{15} \mathrm{~N}$ particles from the ${ }^{2} \mathrm{H}\left({ }^{18} \mathrm{~F}, \alpha+{ }^{15} \mathrm{~N}\right) \mathrm{p}$ reaction. Total running time for the measurement was 117 hours with a beam intensity of $\approx 2 \times 10^{6}$ particles/second. Additional measurements to study background and to calibrate the detectors were also undertaken.

Preliminary results show that the strongest of these two $3 / 2^{+}$states is actually below the separation energy. This is likely to affect reaction rates in this reaction significantly.

This work is part of the Ph.D. project of A. S. Adekola of Ohio University.

\subsection{Measurement of the $183-\mathrm{keV}$ Resonance in the ${ }^{17} \mathrm{O}(\mathrm{p}, \alpha)$ Reaction}

Work performed in collaboration with B. H. Moazen, D. W. Bardayan, J. C. Blackmon, K. Y. Chae, K. Chipps, C. P. Domizioli, R. Fitzgerald, U. Greife, K. L. Jones, R. L. Kozub, R. J. Livesay, C. D. Nesaraja, S. D. Pain, M. S. Smith, and J. S. Thomas

The rates of the ${ }^{17} \mathrm{O}(\mathrm{p}, \alpha)$ and ${ }^{17} \mathrm{O}(\mathrm{p}, \gamma)$ reactions play an important role in understanding giant stars and novae. In particular, for reaction rates at temperatures $\approx 1-4 \mathrm{GK}$, a resonance at $E_{c m}=183 \mathrm{keV}$ in the ${ }^{17} \mathrm{O}(\mathrm{p}, \alpha)$ reaction is especially critical. A recent direct measurement of this reaction by Chafa et al. $[51,52]$ found a resonance strength $\approx 50$ times greater than what had been inferred from a previous measurement $[53,54]$ of the ${ }^{17} \mathrm{O}(\mathrm{p}, \gamma)$ reaction.

Because of the discrepancy in reaction strengths and because of the significant impact on nucleosynthesis of this reaction strength, a new measurement has been performed. The measurement utilized the ${ }^{17} \mathrm{O}$ beam at HRIBF and a large differentially-pumped scattering chamber pressurized with ultra-high purity hydrogen gas at a pressure of 4 torr. No windows or foils were utilized, meaning that backgrounds from contaminants were significantly reduced compared to solid targets or gas cells. Both the $\alpha$ and ${ }^{14} \mathrm{~N}$ particles were detected in coincidence by an array of silicon strip detectors operating within the hydrogen gas environment. Because of the large volume of hydrogen, each segment of the detector viewed the reaction products over a range of angles, depending upon where in the chamber the reaction occurred. However, the scattering angle of each event can still be determined from the energy of the $\alpha$ particle because that energy varies so rapidly with angle. The clean backgrounds and the possibility of easily adjusting target thickness by varying the gas pressure allow this technique to achieve high sensitivity for narrow resonances in $(\mathrm{p}, \alpha)$ reactions studied in inverse kinematics.

The resonance strength was determined to be $\omega \gamma_{p \alpha}=\left(1.70 \pm 0.09_{\text {stat }} \pm 0.12_{\text {sys }}\right) \mathrm{meV}$; this confirms Chafa's recent measurement of $\omega \gamma_{p \alpha}=(1.6 \pm 0.2) \mathrm{meV}$. It also shows the validity of the technique. This work is part of the Ph.D. project of B. H. Moazen of the University of Tennessee. This results has been published in Phys. Rev. C [55]. 


\subsection{Spectroscopic Study of Low-lying ${ }^{16} \mathrm{~N}$ Levels}

Work performed in collaboration with D. W. Bardayan, P. D. O'Malley, J. C. Blackmon, K. Y. Chae, K. A. Chipps, J. A. Cizewski, R. Hatarik, K. L. Jones, R. L. Kozub, C. Matei, B. H. Moazen, C. D. Nesaraja, S. D. Pain, S. Paulauskas, W. A. Peters, S. T. Pittman, K. T. Schmitt, and M. S. Smith

The ${ }^{15} \mathrm{~N}(\mathrm{n}, \gamma)$ reaction is believed to play an important role in the production of ${ }^{19} \mathrm{~F}$ in asymptotic giant branch (AGB) stars. The rate of this reaction in turn depends on the neutron spectroscopic factors. However, the measured values for these spectroscopic factors are rather old [56] and were in sharp disagreement with calculated values [57].

We measured the ${ }^{15} \mathrm{~N}(\mathrm{~d}, \mathrm{p}){ }^{16} \mathrm{~N}$ reaction in inverse kinematics at the Holifield Radioactive Ion Beam Facility (HRIBF) at Oak Ridge National Laboratory. A $100-\mathrm{MeV}{ }^{15} \mathrm{~N}$ beam bombarded a $90-\mu \mathrm{g} / \mathrm{cm}^{2} \mathrm{CD}_{2}$ target. Protons were detected at backward laboratory angles in the range $155-169^{\circ}$ with the SIDAR array; some of the data were taken in coincidence with ${ }^{16} \mathrm{~N}$ recoils detected by the Daresbury Recoil Separator. Additional silicon detectors of the ORRUBA system were utilized near $90^{\circ}$. Data were taken for approximately $65 \mathrm{~h}$, and approximately $4.6 \times 10^{11}{ }^{15} \mathrm{~N}$ ions struck the target.

Spectroscopic factors were determined for the four lowest states in ${ }^{16} \mathrm{~N}$. The new experimental values are near unity and in much better agreement with the theoretical calculations than the previous measurements. These revised results increase the ${ }^{15} \mathrm{~N}(\mathrm{n}, \gamma)$ reaction rate by roughly a factor of two over previous estimates [57]. These results have been published in Phys. Rev. C [58].

\subsection{Measurement of the ${ }^{17} \mathbf{F}(\mathbf{p}, \gamma)$ Cross Section near the $E_{c m}=600 \mathrm{keV}$ Resonance}

Work performed in collaboration with K. A. Chipps, D. W. Bardayan, J. C. Blackmon, K. Y. Chae, U. Greife, R. Hatarik, R. L. Kozub, C. Matei, B. H. Moazen, C. D. Nesaraja, S. D. Pain, W. A. Peters, S. T. Pittman, and M. S. Smith

The rate of the ${ }^{17} \mathrm{~F}(\mathrm{p}, \gamma)$ reaction is important in several different types of astrophysical events, including novae and x-ray bursts. We have recently measured this reaction at the $E_{c m}=599.8 \mathrm{keV}$ resonance. This $3^{+}$state is the most important contributor to this reaction at the temperatures typical of the scenarios in question. Two theoretical calculations $[59,60]$ had estimated the $\gamma$-ray width to be $25 \mathrm{meV}$ and $33 \mathrm{meV}$, respectively. However, a direct measurement had been lacking.

We studied this reaction using a ${ }^{17} \mathrm{~F}$ beam produced at the HRIBF. The beam was accelerated into a differentially pumped, windowless hydrogen gas target. The Daresbury Recoil Separator was used to detect the recoil ${ }^{18} \mathrm{Ne}$ ions as well as the unreacted beam particles.

We found a $(\mathrm{p}, \gamma)$ resonance strength of $\omega \gamma=33 \pm 14$ (stat) \pm 17 (syst) $\mathrm{meV}$, corresponding to $\Gamma_{\gamma}=56 \pm 24$ (stat) \pm 30 (syst) $\mathrm{meV}$; both values are roughly twice the previous estimates. The reaction rate at nova temperatures increases accordingly. More details are available in an article published in Phys. Rev. Lett. [61]. 


\subsection{Nuclear Structure near ${ }^{132} \mathrm{Sn}$ with Transfer Reactions}

Work performed in collaboration with K. L. Jones, R. L. Kozub, S. D. Pain, A. S. Adekola, D. W. Bardayan, J. C. Blackmon, C. R. Brune, K. Y. Chae, K. Chipps, J. A. Cizewski, L. Erikson, R. P. Fitzgerald, A. L. Gaddis, U. Greife, C. Harlin, R. Hatarik, J. A. Howard, W. Krolas, F. J. Liang, R. J. Livesay, Z. Ma, C. Matei, B. H. Moazen, C. D. Nesaraja, P. D. O'Malley, N. P. Patterson, D. Shapira, M. S. Smith, T. P. Swan, and J. S. Thomas

Because the path of the r-process passes far from nuclear stability, it has always been difficult to determine experimentally the relevant structure information for nuclides on or near the path. Where level densities for resonances are high, statistical models can be very helpful. However, level densities are lower near closed shells; there experimental single-particle structure information becomes of vital importance. The use of radioactive beams is beginning to provide information to address some of these questions. Of course, structure information near closed shells not only is of astrophysical relevance but also provides new tests of how shell structure evolves as nuclei move away from stability.

Recently, data have been collected at HRIBF in inverse kinematics for the ${ }^{132} \mathrm{Sn}(\mathrm{d}, \mathrm{p}),{ }^{130} \mathrm{Sn}(\mathrm{d}, \mathrm{p})$, and ${ }^{134} \mathrm{Te}(\mathrm{d}, \mathrm{p})$ reactions. Each of these experiments should provide new information on how the shell structure is evolving near the doubly magic nuclide ${ }^{132} \mathrm{Sn}$. The experiments used beams with energies of $\approx 5 \mathrm{MeV} / A$ incident on $\mathrm{CD}_{2}$ targets. Protons were detected by an array of silicon detectors (an early implementation of the ORRUBA array) at lab angles around $90^{\circ}$. Downstream from the target were an annular silicon strip detector, a carbon-foil microchannel plate detector, and a segmented-anode ion counter for diagnostic and normalization purposes.

Preliminary analysis suggests that four final states were observed in each of the three nuclei; so far these appear to be the $f_{7 / 2}, p_{1 / 2}, p_{3 / 2}$ and $f_{5 / 2}$ excited states. More detailed analyses are in progress. The principal investigators for these measurements are Kate Jones $\left({ }^{133} \mathrm{Sn}\right)$, Ray Kozub $\left({ }^{131} \mathrm{Sn}\right)$, and Steve Pain $\left({ }^{135} \mathrm{Te}\right)$.

\subsection{Elastic Scattering of Protons from ${ }^{25} \mathrm{Al}$}

Work performed in collaboration with D. W. Bardayan, J. C. Blackmon, C. R. Brune, K. Y. Chae, A. E. Champagne, U. Greife, K. L. Jones, R. L. Kozub, R. J. Livesay, B. H. Moazen, C. D. Nesaraja, S. D. Pain, F. Sarazin, D. Shapira, M. S. Smith, and J. S. Thomas

The nuclide ${ }^{26} \mathrm{Al}$ has a half life of $7.2 \times 10^{5}$ years in its ground state and has been observed in abundance in our galaxy [62]. However, its exact method of production continues to be debated. One proposed source is nova explosions [63], where the reaction pathway would be

$$
{ }^{24} \mathrm{Mg}(\mathrm{p}, \gamma)^{25} \mathrm{Al}\left(\beta^{+} \nu_{e}\right)^{25} \mathrm{Mg}(\mathrm{p}, \gamma){ }^{26} \mathrm{Al}^{g . s .}\left(\beta^{+} \nu_{e}\right)^{26} \mathrm{Mg}^{*}(\gamma)^{26} \mathrm{Mg}^{g . s .} .
$$

However, a key uncertainty in this path is the ratio of the ${ }^{25} \mathrm{Al}(\mathrm{p}, \gamma)$ rate to that of the ${ }^{25} \mathrm{Al}\left(\beta^{+} \nu_{e}\right)$ rate. If the capture rate is significantly higher than the $\beta$-decay rate, then little ${ }^{26} \mathrm{Al}^{\text {g.s. }}$ will be produced from this reaction sequence, and the pathway instead will predominantly proceed via

$$
{ }^{24} \operatorname{Mg}(\mathrm{p}, \gamma){ }^{25} \mathrm{Al}(\mathrm{p}, \gamma){ }^{26} \operatorname{Si}\left(\beta^{+} \nu_{e}\right){ }^{26 m} \operatorname{Al}\left(\beta^{+} \nu_{e}\right){ }^{26} \mathrm{Mg} g . s .
$$

Recent work [64] indicates that the current uncertainty in the ${ }^{25} \mathrm{Al}(\mathrm{p}, \gamma){ }^{26} \mathrm{Si}$ cross section is especially key to addressing this question. 
At stellar environments with higher temperatures, such as would occur in X-ray bursts, a different reaction sequence that also involves ${ }^{26} \mathrm{Si}$ is expected. Light elements are converted to heavier elements via a series of $\alpha$ and proton induced reactions:

$$
{ }^{14} \mathrm{O}(\alpha, \mathrm{p}){ }^{17} \mathrm{~F}(\mathrm{p}, \gamma){ }^{18} \mathrm{Ne}(\alpha, \mathrm{p}){ }^{21} \mathrm{Na}(\mathrm{p}, \gamma){ }^{22} \mathrm{Mg}(\alpha, \mathrm{p}){ }^{25} \mathrm{Al}(\mathrm{p}, \gamma){ }^{26} \mathrm{Si} \ldots
$$

Information about both the ${ }^{25} \mathrm{Al}(\mathrm{p}, \gamma)$ and ${ }^{25} \mathrm{Al}(\mathrm{p}, \alpha)$ cross sections would be useful in helping to understand this sequence of reactions.

A proposal for beam time at the HRIBF to study the ${ }^{25} \mathrm{Al}\left({ }^{1} \mathrm{H}, \mathrm{p}\right)$ reaction at $122 \mathrm{MeV}$ has been approved. The beam will be stopped in the target, allowing states in the range $E_{x}=5.5-10.2 \mathrm{MeV}$ in ${ }^{26} \mathrm{Si}$ to be populated. Scattered protons will be detected over an angular range of $\theta_{l a b}=25^{\circ}-60^{\circ}$ using the SIDAR array. SIDAR will be configured with $500-\mu \mathrm{m}$-thick detectors backed by $1000-\mu \mathrm{m}-$ thick detectors of Micron Semiconductor Style YY1. Thirteen 8-hour shifts of beam time have been allotted for this measurement. The scheduling of this experiment is unknown. 


\section{References}

[1] S. C. Frankle, G. E. Mitchell, J. F. Shriner, Jr., E. G. Bilpuch, and C. R. Westerfeldt. Phys. Rev. C 45, 2746 (1992).

[2] J. F. Shriner, Jr., E. G. Bilpuch, C. R. Bybee, G. E. Mitchell, E. F. Moore, J. D. Shriner, and C. R. Westerfeldt. Nucl. Instrum. Methods "B99", 641 (1995).

[3] P. M. Wallace, E. G. Bilpuch, C. R. Bybee, G. E. Mitchell, E. F. Moore, J. D. Shriner, J. F. Shriner, Jr., G. A. Vavrina, and C. R. Westerfeldt. Phys. Rev. C 54, 2916 (1996).

[4] G. A. Vavrina, E. G. Bilpuch, C. R. Bybee, G. E. Mitchell, E. F. Moore, J. D. Shriner, J. F. Shriner, Jr., P. M Wallace, and C. R. Westerfeldt. Phys. Rev. C 55, 1119 (1997).

[5] C. A. Grossmann, M. A. LaBonte, G. E. Mitchell, J. D. Shriner, J. F. Shriner, Jr., G. A. Vavrina, and P. M. Wallace. Phys. Rev. C 62, 024323 (2000).

[6] G. E. Mitchell, E. G. Bilpuch, P. M. Endt, and J. F. Shriner, Jr. Phys. Rev. Lett. 61, 1473 (1988).

[7] J. F. Shriner, Jr., E. G. Bilpuch, P. M. Endt, and G. E. Mitchell. Z. Phys. A 335, 393 (1990).

[8] F. J. Dyson. J. Math. Phys. 3, 1191 (1962).

[9] A. Pandey. Ann. Phys. (N.Y.) 134, 110 (1981).

[10] T. Guhr and H. A. Weidenmüller. Ann. Phys. (N.Y.) 199, 412 (1990).

[11] C. Ellegaard, T. Guhr, K. Lindemann, J. Nygård, and M. Oxborrow. Phys. Rev. Lett. 77, 4918 (1996).

[12] H. Alt, C. I. Barbosa, H.-D. Gräf, T. Guhr, H. L. Harney, R. Hofferbert, H. Rehfeld, and A. Richter. Phys. Rev. Lett. 81, 4847 (1998).

[13] T. Guhr, A. Müller-Groeling, and H. Weidenmüller. Phys. Rep. 299, 189 (1998).

[14] J. F. Shriner, Jr., C. A. Grossmann, and G. E. Mitchell. Phys. Rev. C 62, 054305 (2000).

[15] Y. Alhassid and M. Feingold. Phys. Rev. A 39, 374 (1989).

[16] Y. Alhassid and A. Novoselsky. Phys. Rev. C 45, 1677 (1992).

[17] A. A. Adams, G. E. Mitchell, W. E. Ormand, and J. F. Shriner, Jr. Phys. Lett. B 392, 1 (1997).

[18] P. M. Endt, P. de Wit, and C. Alderliesten. Nucl. Phys. A476, 333 (1988).

[19] P. M. Endt, P. de Wit, C. Alderliesten, and B. H. Wildenthal. Nucl. Phys. A487, 221 (1988).

[20] P. M. Endt. Nucl. Phys. A521, 1 (1990).

[21] C. Iliadis, L. Buchmann, P. M. Endt, H. Herndl, and M. Wiescher. Phys. Rev. C 53, 475 (1996).

[22] A. A. Adams, G. E. Mitchell, and J. F. Shriner, Jr. Phys. Lett. B 422, 13 (1998).

[23] C. I. Barbosa, T. Guhr, and H. L. Harney. Phys. Rev. E 62, 1936 (2000).

[24] M. S. Hussein and M. P. Pato. Phys. Rev. Lett. 84, 3873 (2000). 
[25] C. Dembowski. Dissipation in Mikrowellenbilliards. Ph.D. thesis, Technische Universität Darmstadt (2003).

[26] W.D.M. Rae, A. Etchegoyen, and B. A. Brown. OXBASH, the Oxford-Buenos Aires-MSU shellmodel code. Technical Report 524, Michigan State University Cyclotron Laboratory (1985).

[27] W. E. Ormand and B. A. Brown. Nucl. Phys. A491, 1 (1989).

[28] J. F. Shriner, Jr. and G. E. Mitchell. Z. Phys. A 342, 53 (1992).

[29] J. F. Shriner, Jr., G. E. Mitchell, and B. A. Brown. Phys. Lett B586, 232 (2004).

[30] J. F. Shriner, Jr., G. E. Mitchell, and B. A. Brown. Phys. Rev. C 71, 024313 (2005).

[31] F. J. Dyson. J. Math. Phys. 3, 140 (1962).

[32] F. J. Dyson. J. Math. Phys. 3, 157 (1962).

[33] F. J. Dyson. J. Math. Phys. 3, 166 (1962).

[34] U. Agvaanluvsan, G. E. Mitchell, J. F. Shriner, Jr., and M. Pato. Nucl. Instrum. Methods A498, 459 (2003).

[35] J. F. Shriner, Jr., M. P. Pato, G. E. Mitchell, and A. P. B. Tufaile. Nucl. Insrum. Methods A581, 831 (2007).

[36] C. E. Porter and R. G. Thomas. Phys. Rev. 104, 483 (1956).

[37] U. Agvaanluvsan, G. E. Mitchell, J. F. Shriner, Jr., and M. Pato. Phys. Rev. C 67, 064608 (2003).

[38] F. J. Dyson and M. L. Mehta. J. Math. Phys. 4, 701 (1963).

[39] M. L. Mehta. Random Matrices. Academic, New York, second edition (1991).

[40] S. J. Lokitz, G. E. Mitchell, and J. F. Shriner Jr. Phys. Lett. B 599, 223 (2004).

[41] S. J. Lokitz, G. E. Mitchell, and J. F. Shriner Jr. Phys. Rev. C 71, 064315 (2005).

[42] M. J. Harris, J. E. Naya, B. J. Teegarden, T. L. Cline, N. Gehrels, D. M. Palmer, R. Ramaty, and H. Seifert. Astrophys. J. 522, 424 (1999).

[43] M. Hernanz, J. Gómez-Gomar, and J. José. New Astronomy Reviews 46, 559 (2002).

[44] D. W. Bardayan, J. C. Blackmon, W. Bradfield-Smith, C. R. Brune, A. E. Champagne, T. Davinson, B. A. Johnson, R. L. Kozub, C. S. Lee, R. Lewis, P. D. Parker, A. C. Shotter, M. S. Smith, D. W. Visser, and P. J. Woods. Phys. Rev. C 63, 065802 (2001).

[45] D. W. Bardayan, J. C. Blackmon, A. E. Champagne, A. K. Dummer, T. Davinson, U. Greife, D. Hill, C. Iliadis, B. A. Johnson, R. L. Kozub, C. S. Lee, M. S. Smith, and P. J. Woods. Phys. Rev. C 65, 032801(R) (2002).

[46] N. de Séréville et al.. Phys. Rev. C 67, 052801(R) (2003).

[47] R. L. Kozub, D. W. Bardayan, J. C. Batchelder, J. C. Blackmon, C. R. Brune, A. E. Champagne, J. A. Cizewski, T. Davinson, U. Greife, C. J. Gross, C. C. Jewett, R. J. Livesay, Z. Ma, B. H. Moazen, C. D. Nesaraja, L. Sahin, J. P. Scott, D. Shapira, M. S. Smith, J. S. Thomas, and P. J. Woods. Phys. Rev. C 71, 032801(R) (2005). 
[48] M. Wiescher and K.-U. Kettner. Astrophys. J. 263, 891 (1982).

[49] N. de Séréville, E. Berthoumieux, and A. Coc. Nucl. Phys. A758, 745c (2005).

[50] K. Y. Chae, D. W. Bardayan, J. C. Blackmon, D. Gregory, M. W. Guidry, M. S. Johnson, R. L. Kozub, R. J. Livesay, Z. Ma, C. D. Nesaraja, S. D. Pain, S. Paulauskas, M. Porter-Peden, J. F. Shriner, Jr., N. Smith, M. S. Smith, and J. S. Thomas. Phys. Rev. C 74, 012801(R) (2006).

[51] A. Chafa, V. Tatischeff, P. Aguer, S. Barhoumi, A. Coc, F. Garrido, M. Hernanz, J. José, J. Kiener, A. Lefebvre-Schuhl, S. Ouichaoui, N. de Séréville, and J.-P. Thibaud. Phys. Rev. Lett 95, 031101 (2005).

[52] A. Chafa, V. Tatischeff, P. Aguer, S. Barhoumi, A. Coc, F. Garrido, M. Hernanz, J. José, J. Kiener, A. Lefebvre-Schuhl, S. Ouichaoui, N. de Séréville, and J.-P. Thibaud. Phys. Rev. Lett 96, 019902 (2006).

[53] C. Fox, C. Iliadis, A. E. Champagne, A. Coc, J. José, R. Longland, J. Newton, J. Pollanen, and R. Runkle. Phys. Rev. Lett 93, 081102 (2004).

[54] C. Fox, C. Iliadis, A. E. Champagne, R. P. Fitzgerald, R. Longland, J. Newton, J. Pollanen, and R. Runkle. Phys. Rev. C 71, 055801 (2005).

[55] B. H. Moazen, D. W. Bardayan, J. C. Blackmon, K. Y. Chae, K. Chipps, C. P. Domizioli, R. Fitzgerald, U. Greife, W. R. Hix, K. L. Jones, R. L. Kozub, E. J. Lingerfelt, R. J. Livesay, C. D. Nesaraja, S. D. Pain, L. F. Roberts, Jr. J. F. Shriner, M. S. Smith, , and J. S. Thomas. Phys. Rev. C 75, 065801 (2007).

[56] W. Bohne, J. Bommer, H. Fuchs, K. Grabisch, H. Kluge, and G. Röschert. Nucl. Phys. A 196, 41 (1972).

[57] J. Meissner, H. Schatz, H. Herndl, M. Wiescher, H. Beer, and F. Käppeler. Phys. Rev. C 53, 977 (1996).

[58] D. W. Bardayan, P. D. O’Malley, J. C. Blackmon, K. Y. Chae, K. A. Chipps, J. A. Cizewski, R. Hatarik, K. L. Jones, R. L. Kozub, C. Matei, B. H. Moazen, C. D. Nesaraja, S. D. Pain, S. Paulauskas, W. A. Peters, S. T. Pittman, K. T. Schmitt, J. F. Shriner, Jr., and M. S. Smith. Phys. Rev. C 78, 052801(R) (2008).

[59] A. García, E. G. Adelberger, P. V. Magnus, D. M. Markoff, K. B. Swartz, M. S. Smith, K. I. Hahn, N. Bateman, and P. D. Parker. Phys. Rev. C 43, 2012 (1991).

[60] M. Dufour and P. Descouvemont. Nucl Phys. A 730, 316 (2004).

[61] K. A. Chipps, D. W. Bardayan, J. C. Blackmon, K. Y. Chae, U. Greife, R. Hatarik, R. L. Kozub, C. Matei, B. H. Moazen, C. D. Nesaraja, S. D. Pain, W. A. Peters, S. T. Pittmann, J. F. Shriner, Jr., and M. S. Smith. Phys. Rev. Lett. 102, 152502 (2009).

[62] R. Diehl, K. Bennett, H. Bloemen, H. deBoer, M. Busetta, W. Collmar, A. Connors, J. W. denHerder, C. deVries, W. Hermsen, J. Knödlseder, L. Kuiper, G. G. Lichti, J. Lockwood, J. Macri, M. McConnell, D. Morris, R. Much, J. Ryan, V. Schönfelder, G. Simpson, J. G. Stacy, H. Steinle, A. W. Strong, B. N. Swanenburg, M. Varendorff, P. von Ballmoos, W. Webber, and C. Winckler. Astron. Astrophys. Suppl. 97, 181 (1993).

[63] R. D. Gehrz, J. W. Truran, R. E. Williams, and S. Starrfield. Publ. Astron. Soc. Pac. 110, 3 (1998).

[64] J. José, A. Coc, and M. Hernanz. Astrophys. J. 520, 347 (1999). 


\section{Appendix I}

\section{Publications and Presentations under Grant DE-FG02-96ER40990}

\section{Articles}

- "Parity violation in charged-particle resonance reactions," G. E. Mitchell and J. F. Shriner, Jr., Phys. Rev. C 54, 371 (1996).

- "The Fourier Transform as a Signature for Chaos in Nuclear Energy Levels," C. R. Bybee, G. E. Mitchell, and J. F. Shriner, Jr., Z. Phys. A 355, 327 (1996).

- "Spectroscopy of the ${ }^{29} \mathrm{Si}(p, \gamma)$ Reaction for $E_{p}=1.75-2.51 \mathrm{MeV}$," P. M. Wallace, E. G. Bilpuch, C. R. Bybee, G. E. Mitchell, E. F. Moore, J. D. Shriner, J. F. Shriner, Jr., G. A. Vavrina, and C. R. Westerfeldt, Phys. Rev. C 54, 2916 (1996).

- "Spectroscopy of the ${ }^{29} \mathrm{Si}(\mathrm{p}, \gamma)$ Reaction for $\mathrm{E}_{p}=1.001 .75 \mathrm{MeV}$," G. A. Vavrina, E. G. Bilpuch, C. R. Bybee, G. E. Mitchell, E. F. Moore, J. D. Shriner, J. F. Shriner, Jr., P. M. Wallace, and C. R. Westerfeldt, Phys. Rev. C 55, 1119 (1997).

- "Distribution of Shell Model Reduced Transition Probabilities in ${ }^{22} \mathrm{Na}, "$ A. A. Adams, G. E. Mitchell, W. E. Ormand, and J. F. Shriner, Jr., Phys. Lett. B 392, 1 (1997).

- "Statistical Distribution of Reduced Transition Probabilities in ${ }^{26} \mathrm{Al}$," A. A. Adams, G. E. Mitchell, and J. F. Shriner, Jr., Phys. Lett. B 422, 13 (1998).

- "Complete Spectroscopy of ${ }^{30}$ P," C. A. Grossmann, M. A. LaBonte, G. E. Mitchell, J. D. Shriner, J. F. Shriner, Jr., G. A. Vavrina, and P. M. Wallace, Phys. Rev. C 62, $024323(2000)$.

- "Level Statistics and Transition Distributions of ${ }^{30} \mathrm{P}$," J. F. Shriner, Jr., C. A. Grossmann, and G. E. Mitchell, Phys. Rev. C 62, 054305 (2000).

- "Missing Level Corrections in Nuclear Resonances," U. Agvaanluvsan, G. E. Mitchell, J. F. Shriner, Jr., and M. P. Pato, Nucl. Instrum. and Methods A498, 459 (2003).

- "Parity Dependence of Nuclear Level Densities," U. Agvaanluvsan, G. E. Mitchell, J. F. Shriner, Jr., and M. Pato, Phys. Rev. C 67, 064608 (2003).

- "Isospin Symmetry Breaking and the Nuclear Shell Model," J. F. Shriner, Jr., G. E. Mitchell, and B. A. Brown, Phys. Lett. B 586, 232 (2004).

- "Parity Dependence of ${ }^{45}$ Sc Level Densities," S. J. Lokitz, G. E. Mitchell, and J. F. Shriner, Jr., Phys. Lett. B 599, 223 (2004).

- "Statistical Properties and Broken Symmetries within the Shell Model," J. F. Shriner, Jr., G. E. Mitchell, and B. A. Brown, Phys. Rev. C 71, 024313 (2005).

- "Test of ${ }^{45} \mathrm{Sc}$ Level Densities with Proton Resonances," S. J. Lokitz, G. E. Mitchell, J. F. Shriner, Jr., Phys. Rev. C 71, 064315 (2005).

- "First Experimental Constraints on the Interference of 3/2+ Resonances in the ${ }^{18} \mathrm{~F}(\mathrm{p}, \alpha)$ Reaction," K. Y. Chae, D. W. Bardayan, J. C. Blackmon, D. Gregory, M. W. Guidry, M. S. Johnson, R. L. Kozub, R. J. Livesay, Z. Ma, C. D. Nesaraja, S. D. Pain, S. Paulauskas, M. Porter-Peden, J. F. Shriner, Jr., N. Smith, M. S. Smith, and J. S. Thomas, Phys Rev. C 74, 012801(R) (2006). 
- "Measurement of the $183 \mathrm{keV}$ resonance in ${ }^{17} \mathrm{O}(\mathrm{p}, \alpha){ }^{14} \mathrm{~N}$ using a novel technique," B. H. Moazen, D. W. Bardayan, J. C. Blackmon, K. Y. Chae, K. Chipps, C. P. Domizioli, R. Fitzgerald, U. Greife, W. R. Hix, K. L. Jones, R. L. Kozub, E. J. Lingerfelt, R. J. Livesay, C. D. Nesaraja, S. D. Pain, L. F. Roberts, J. F. Shriner, Jr., M. S. Smith, and J. S. Thomas, Phys. Rev. C 75, 065801 (2007).

- "A Thermodynamic Analysis of Energy Eigenvalues," J. F. Shriner, Jr., M. P. Pato, G. E. Mitchell, and A. P. B. Tufaile, Nucl. Instrum. and Methods A581, 831 (2007).

- "Spectroscopic study of low-lying ${ }^{16} \mathrm{~N}$ levels," D. W. Bardayan, P. D. O'Malley, J. C. Blackmon, K. Y. Chae, K. A. Chipps, J. A. Cizewski, R. Hatarik, K. L. Jones, R. L. Kozub, C. Matei, B. H. Moazen, C. D. Nesaraja, S. D. Pain, S. Paulauskas, W. A. Peters, S. T. Pittman, K. T. Schmitt, J. F. Shriner, Jr., and M. S. Smith, Phys. Rev. C 78, 052801(R), 2008

- "First Direct Measurement of the ${ }^{17} \mathrm{~F}(\mathrm{p}, \gamma){ }^{18} \mathrm{Ne}$ Cross Section," K. A. Chipps, D. W. Bardayan, J. C. Blackmon, K. Y. Chae, U. Greife, R. Hatarik, R. L. Kozub, C. Matei, B. H. Moazen, C. D. Nesaraja, S. D. Pain, W. A. Peters, S. T. Pittman, J. F. Shriner, Jr., and M. S. Smith, Phys. Rev. Lett. 102, 152502 (2009).

\section{Publications in Conference Proceedings}

- "A Complete Level Scheme for ${ }^{30}$ P," J. F. Shriner, Jr., J. M. Cox, L. M. Fittje, C. R. Bybee, M. A. LaBonte, E. F. Moore, G. E. Mitchell, J. D. Shriner, G. A. Vavrina, E. G. Bilpuch, and P. M. Wallace, Proceedings of the 9th International Symposium on Capture Gamma-ray Spectroscopy and Related Topics, eds. G. L. Molnár, T. Belgya, and Zs. Révay, Springer-Verlag (Budapest), 1997, p. 467.

- "Techniques for Precision Measurements of Parity Violating Asymmetries, W. S. Wilburn, G. E. Mitchell, N. R. Roberson, and J. F. Shriner, Jr., Application of Accelerators in Research and Industry, ed. by J. L. Duggan and I. L. Morgan, AIP Press (New York), 1997, p. 297.

- "Proton Capture Resonance Studies," G. E. Mitchell, E. G. Bilpuch, C. R. Bybee, J. M. Cox, L. M. Fittje, M. A. LaBonte, E. F. Moore, J. D. Shriner, J. F. Shriner, Jr., G. A. Vavrina, and P. M. Wallace, Application of Accelerators in Research and Industry, ed. by J. L. Duggan and I. L. Morgan, AIP Press (New York), 1997, p. 281.

- "Fluctuation Properties of Nuclear Levels and Transitions," G. E. Mitchell and J. F. Shriner, Jr., Proceedings of the Fifth Wigner Symposium, eds. P. Kasperkovitz and D. Grau, World Scientific (Singapore), 1998, p. 274.

- "Parity Violation in 2s-1d Nuclei using the $(\mathrm{p}, \alpha)$ Reaction," B. E. Crawford, G. E. Mitchell, N. R. Roberson, J. F. Shriner, Jr., L. K. Warman, and W. S. Wilburn, Applications of Accelerators in Research and Industry, eds. J. L. Duggan and I. L. Morgan, AIP Press (New York), 1999, p. 235.

- "Effects of Isospin Mixing on Statistical Properties of ${ }^{26} \mathrm{Al}$ and ${ }^{30} \mathrm{P}$," J. F. Shriner, Jr., M. A. Blackston, C. A. Grossmann, K. T. Mahar, and G. E. Mitchell, Capture Gamma-ray Spectroscopy and Related Topics, ed. Stephen Wender, AIP Press (New York), 2000, p.497.

- "Effect of Symmetry Breaking on Statistical Distributions," G. E. Mitchell and J. F. Shriner, Jr., Physica Scripta T90, 105 (2001).

- "Effect of Symmetry Breaking on Transition Strength Distributions," G. E. Mitchell and J. F. Shriner, Jr., Application of Accelerators in Research and Industry: Sixteenth International Conference, Eds. J. L. Duggan and I. L. Morgan, AIP Press (New York), 2001, p. 331. 
- "Determining Nuclear Level Densities," G. E. Mitchell, U. Agvaanluvsan, J. F. Shriner, Jr., and M. Pato, Capture Gamma-Ray Spectroscopy And Related Topics: Proceedings of the Eleventh International Symposium, eds. J. Kvasil, P. Cejnar and M. Krticka, World Scientific (Singapore), 2003, p. 382

- "Statistical Aspects of the Shell Model: Broken Isospin Symmetry," J. F. Shriner, Jr., G. E. Mitchell, and B. A. Brown, Capture Gamma-Ray Spectroscopy And Related Topics: Proceedings of the Eleventh International Symposium, eds. J. Kvasil, P. Cejnar and M. Krticka, World Scientific (Singapore), 2003, p. 389

- "Level Densities from Proton Resonances," U. Agvaanluvsan, G. E. Mitchell, J. F. Shriner, Jr., and M. Pato, Application of Accelerators in Research and Industry: Seventeenth International Conference on the Application of Accelerators in Research and Industry, eds. J. L. Duggan and I. L. Morgan, AIP Press (New York), 2003, p. 321.

- "Missing and Spurious Levels in Nuclear Resonances," G. E. Mitchell, S. J. Lokitz, U. Agvaanluvsan, M. Pato, and J. F. Shriner, Jr., Proceedings of the XII International Seminar on Interactions of Neutrons with Nuclei, ISINN-XII, E3-2004-169, Joint Institute of Nuclear Physics (Dubna), 2004, p. 87.

- "Statistical Behavior and Symmetry Tests," G. E. Mitchell and J. F. Shriner, Jr., Braz. J. Phys. 34, 796 (2004).

- "Improved Nuclear Level Densities via Identification of Spurious Levels," U. Agvaanluvsan, G. E. Mitchell, D. Dashdorj, C. M. Frankle, S. J. Lokitz, and J. F. Shriner, Jr., International Conference on Nuclear Data for Science and Technology, eds. R. C. Haight, P. Talou, T. Kawano, and M. B. Chadwick, AIP Press (New York), 2005, p. 1164.

- "Missing and Spurious Level Corrections for Nuclear Resonances," G. E. Mitchell, U. Agvaanluvsan, M. P. Pato, and J. F. Shriner, Jr., Proceedings of International School on Contemporary Physics-III, eds. G. Khuukhenkhuu and J. Vanchinkhuu, University Press (Ulanbataar), 2005, p. 179

- "Proton Capture on ${ }^{48}$ Ti," G. E. Mitchell, D. B. McDevitt, J. F. Shriner, Jr., Proceedings of the XIII International Seminar on Interactions of Neutrons with Nuclei, ISINN-13, E3-2006-7, Joint Institute for Nuclear Research, Dubna, 2006, p. 48-56.

- "Study of interference effects in the ${ }^{18} \mathrm{~F}(\mathrm{p}, \alpha){ }^{15} \mathrm{O}$ reaction," K. Y. Chae, M. W. Guidry, C. D. Nesaraja, Z. Ma, D. W. Bardayan, J. C. Blackmon, M. S. Smith D. Gregory, R. L. Kozub, S. Paulauskas, J. F. Shriner, Jr., N. Smith, M. S. Johnson, R. J. Livesay, M. Porter-Peden, S. D. Pain, and J. S. Thomas, Proceedings of International Symposium on Nuclear Astrophysics - Nuclei in the Cosmos - IX, Proceedings of Science (NIC IX) 2006, 273.

- "Single Neutron Transfer Experiments close to the r-Process Path," K. L. Jones, A. S. Adekola, D. W. Bardayan, J. C. Blackmon, K. Y. Chae, K. Chipps, J. A. Cizewski, D. J. Dean, L. Erikson, R. P. Fitzgerald, A. L. Gaddis, U. Greife, C. Harlin, R. Hatarik, J. A. Howard, M. S. Johnson, R. L. Kozub, J. F. Liang, R. J. Livesay, Z. Ma, B. H. Moazen, P. D. O'Malley, C. D. Nesaraja, S. D. Pain, N. P. Patterson, S. V. Paulauskas, D. Shapira, J. F.Shriner, Jr., D. J. Sissom, M. S.Smith, T. P. Swan, and J. S. Thomas, Acta Phys. Pol. B38, 1205 (2007).

- "Thermodynamic Analysis of Spectra," G. E. Mitchell and J. F. Shriner, Jr., Nuclei and Mesoscopic Physics, eds. Pawel Danielewicz, Piotr Piecuch, and Vladimir Zelevinsky, AIP Press (New York), 2008, p. 185. 
- "First Direct Measurement of the ${ }^{17} \mathrm{~F}(\mathrm{p}, \gamma){ }^{18} \mathrm{Ne}$ Cross Section," Kelly Chipps, D. W. Bardayan, C. D. Nesaraja, S. D. Pain, M. S. Smith, J. C. Blackmon, K. Y. Chae, B. H. Moazen, S. T. Pittman, U. Greife, R. Hatarik, W. A. Peters, R. L. Kozub, J. F. Shriner, Jr., and C. Matei, Proceedings of the 10th Symposium on Nuclei in the Cosmos, Proceedings of Science (NIC X) 2008, 059.

- "Neutron-spectroscopic factors for low-lying ${ }^{16} \mathrm{~N}$ levels," D. W. Bardayan, P. D. O'Malley, J. C. Blackmon, K. Y. Chae, K. A. Chipps, J. A. Cizewski, R. Hatarik, K. L. Jones, R. L. Kozub, C. Matei, B. H. Moazen, C. D. Nesaraja, S. D. Pain, S. Paulauskas, W. A. Peters, S. T. Pittman, K. T. Schmitt, J. F. Shriner, Jr., and M. S. Smith, Proceedings of the 10th Symposium on Nuclei in the Cosmos, Proceedings of Science (NIC X) 2008, 067.

- "Neutron single particle structure in ${ }^{131} \mathrm{Sn}$ and the r-process," R. L. Kozub, A. S. Adekola, D. W. Bardayan, J. C. Blackmon, K. Y. Chae, K. A. Chipps, J. A. Cizewski, L. Erikson, R. Hatarik, K. L. Jones W. Krolas F. Liang, Z. Ma, C. Matei, B. H. Moazen, C. D. Nesaraja, S. D. Pain, D. Shapira, J. F. Shriner, Jr., M. S. Smith, and T. P. Swan, Proceedings of the 10th Symposium on Nuclei in the Cosmos, Proceedings of Science (NIC X) 2008, 135.

- "Neutron Transfer Measurements on Neutron-rich N=82 Nuclei," S. D. Pain, K. L. Jones, D. W. Bardayan, J. C. Blackmon, K. Y. Chae, K. A. Chipps, J. A. Cizewski, R. Hatarik, R. Kapler, R. L. Kozub, F. Liang, B. H. Moazen, C. D. Nesaraja, D. Shapira, J. F. Shriner, Jr., and M. S. Smith, Proceedings of the 10th Symposium on Nuclei in the Cosmos, Proceedings of Science (NIC X) 2008, 142.

- "Astrophysically important ${ }^{19} \mathrm{Ne}$ states studied with the ${ }^{2} \mathrm{H}\left({ }^{18} \mathrm{~F}, \alpha+{ }^{15} \mathrm{O}\right) \mathrm{n}$ Reaction," A. Adekola, D. W. Bardayan, J. C. Blackmon, C. R. Brune, K. Y. Chae, A. E. Champagne, C. P. Domizioli, U. Greife, Z. Heinen, M. J. Hornish, M. Johnson, K. L. Jones, R. L. Kozub, R. J. Livesay, Z. Ma, T. N. Massey, B. Moazen, C. D. Nesaraja, S. D. Pain, J. F. Shriner, Jr., J. S. Thomas, N. D. Smith, M. S. Smith, D. W. Visser, and A. V. Voinov, Proceedings of the 10th Symposium on Nuclei in the Cosmos, Proceedings of Science (NIC X) 2008, 151.

- "Studies of nuclei close to ${ }^{132} \mathrm{Sn}$ using single-neutron transfer reactions," K. J. Jones, S. D. Pain, R. L. Kozub, A. S. Adekola, D. W. Bardayan, J. C. Blackmon, W. N. Catford, K. Y. Chae, K. Chipps, J. A. Cizewski, L. Erikson, A. L. Gaddis, U. Greife, R. Grzywacz, C. Harlin, R. Hatarik, J. A. Howard, J. James, R. Kapler, W. Krlas, J. F. Liang, Z. Ma, C. Matei, B. H. Moazen, C. D. Nesaraja, P. D. O'Malley, N. P. Patterson, S. V. Paulauskas, D. Shapira, J. F. Shriner, Jr; M. Sikora, D. J. Sissom, M. S. Smith, T. P. Swan, J. S. Thomas, and G. L. Wilson, FUSION08: New Aspects of Heavy Ion Collisions Near the Coulomb Barrier, eds. K. Ernst Rehm, Birger B. Back, Henning Esbensen, and C. J. (Kim) Lister, AIP Press (New York), 2009, p. 153

- "Measurement of the $330 \mathrm{keV}$ Resonance in ${ }^{18} \mathrm{~F}(\mathrm{p}, \alpha){ }^{15} \mathrm{O}$, " B. H. Moazen, J. C. Blackmon, D. W. Bardayan, K. Y. Chae, K. Chipps, K. L. Grzywacz, R. L. Kozub, C. Matei, C. D. Nesaraja, S. D. Pain, J. F. Shriner, Jr., and M. S. Smith, Acta Phys. Pol. B40, 699 (2009).

- "Neutron Transfer Reactions: Surrogates for Neutron Capture for Basic and Applied Nuclear Science," J. A. Cizewski, K. L. Jones, R. L. Kozub, S. D. Pain, W. A. Peters, A. Adekola, J. Allen, D. W. Bardayan, J. A. Becker, J. C. Blackmon, K. Y. Chae, K. A. Chipps, L. Erikson, A. Gaddis, C. Harlin, R. Hatarik, J. Howard, M. Jandel, M. S. Johnson, R. Kapler, W. Krolas, F. Liang, R. J. Livesay, Z. Ma, C. Matei, C. Matthews, B. Moazen, C. D. Nesaraja, P. O'Malley, N. Patterson, S. V. Paulauskas, T. Pelham, S. T. Pittman, D. Radford, J. Rogers, K. Schmitt, D. Shapira, J. F. Shriner, Jr., D. J. Sissom, M. S. Smith, T. Swan, J. S. Thomas, D. J. Vieira, J. B. Wilhelmy, and G. L. Wilson, Application of Accelerators in Research and Industry: 
Twentieth International Conference, eds. Floyd D. McDaniel and Barney L. Doyle, AIP Press (New York), 2009, p. 724.

\section{Dissertations and Theses Supervised}

- Chris Allen Grossmann, "Complete Spectroscopy of ${ }^{30} \mathrm{P}, "$ Ph.D. degree, North Carolina State University, 1999. Supervisors - G. E. Mitchell and J. F. Shriner, Jr.

- Undraa Agvaanluvsan, "Level Density Analysis of Nuclear Resonances," Ph.D. degree, North Carolina State University, 2002. Supervisors - G. E. Mitchell and J. F. Shriner, Jr.

- Daniel B. McDevitt, "Proton Radiative Capture on ${ }^{48}$ Ti," Ph.D. degree, North Carolina State University, 2002. Supervisors - G. E. Mitchell and J. F. Shriner, Jr.

- Stephen Jared Lokitz, "A High-Resolution Study of p $+{ }^{44}$ Ca Reactions," Ph.D. degree, North Carolina State University, 2004. Supervisors - G. E. Mitchell and J. F. Shriner, Jr.

- William Chandler Beal, Jr., "A High-Resolution Study of Proton Resonances in ${ }^{51} \mathrm{Mn}, "$ Ph.D. degree, North Carolina State University, 2004. Supervisors - G. E. Mitchell and J. F. Shriner, Jr.

- Lance McLean "A High-resolution Study of the ${ }^{52} \mathrm{Cr}\left(\mathrm{p}, \mathrm{p}_{0}\right)$ and ${ }^{52} \mathrm{Cr}\left(\mathrm{p}, \mathrm{p}_{1}\right)$ Reactions," Ph.D. degree, North Carolina State University, 2005. Supervisors - G. E. Mitchell and J. F. Shriner, Jr.

\section{Invited Talks}

- "A Complete Level Scheme for ${ }^{30}$ P," J. F. Shriner, Jr., Ninth International Symposium on Capture Gamma-Ray Spectroscopy and Related Topics, Budapest, Hungary, 1996.

- "Effects of Isospin Mixing on Statistical Properties of ${ }^{26} \mathrm{Al}$ and ${ }^{30} \mathrm{P}$," J. F. Shriner, Jr., 10th International Symposium on Capture Gamma-ray Spectroscopy and Related Topics, Santa Fe, NM, 1999.

- "Statistical Aspects of the Shell Model: Broken Isospin Symmetry," 11th International Symposium on Capture Gamma-ray Spectroscopy and Related Topics, Prague, 2002.

- "Research in an Undergraduate Physics Department", Spring APS Meeting, St. Louis, 2008.

\section{Undergraduate Presentations}

- "Parity Violation in Charged-particle Resonances," J. M. Cox, Society of Physics Students meeting in conjunction with SESAPS meeting, Nashville, TN, 1998

- "Effects of Isospin Mixing on the Distribution of Shell-model Transition Probabilities," K. T. Mahar, APS Division of Nuclear Physics Meeting, Pacific Grove, CA, 1999.

- "A High-resolution Study of the ${ }^{52} \mathrm{Cr}\left(\mathrm{p}, \mathrm{p}_{0}\right)$ and ${ }^{52} \mathrm{Cr}\left(\mathrm{p}, \mathrm{p}_{1}\right)$ Reactions," E. D. Lake, APS Division of Nuclear Physics Meeting, Tucson, AZ, 2003.

- "Level Densities in ${ }^{53} \mathrm{Mn}, "$ D. R. Stevens, APS Division of Nuclear Physics Meeting, Tucson, AZ, 2003.

- "Correcting Level Density Measurements for the Effects of Spurious Levels," Jason Knight, APS Division of Nuclear Physics Meeting, Chicago, IL, 2004. 
- "A High-resolution Study of the p $+{ }^{50}$ Cr Reaction," B. A. Schwer, APS Division of Nuclear Physics Meeting, Chicago, IL, 2004.

- "Statistical Analysis of Nucleon Resonances: Updating the Nuclear Data Ensemble," D. J. Sissom, APS Division of Nuclear Physics Meeting, Nashville, TN, 2006.

- "Tests of Spurious Levels for Neutron or Proton Resonance Data," R. C. Roller, APS Division of Nuclear Physics Meeting, Newport News, VA, 2007.

- "Statistical Analysis of Proton and Neutron Resonance Data," D. J. Sissom, APS Division of Nuclear Physics Meeting, Newport News, VA, 2007.

\section{Abstracts}

- "Parity Violation in Charged Particle Resonances," W. S. Wilburn, N. R. Roberson, G. E. Mitchell, and J. F. Shriner, Jr., B.A.P.S. 41, 914 (1996).

- "A High Resolution Study of ${ }^{30}$ P," P. M. Wallace, E. G. Bilpuch, C. R. Westerfeldt, G. E. Mitchell, E. F. Moore, G. A. Vavrina, and J. F. Shriner, Jr., B.A.P.S. 41, 984 (1996).

- "Spectroscopy of ${ }^{30} \mathrm{P}, "$ P. M. Wallace, E. G. Bilpuch, C. R. Bybee, J. D. Shriner, G. E. Mitchell, E. F. Moore, G. A. Vavrina, and J. F. Shriner, Jr., B.A.P.S. 41, 1653 (1996).

- "Level Structure Studies with the GEANIE Detector," W. S. Wilburn, D. M. Drake, G. D. Johns, R. O. Nelson, D. E. Archer, J. A. Becker, L. A. Bernstein, W. Younes, G. E. Mitchell, N. R. Roberson, and J. F. Shriner, Jr., B.A.P.S. 42, 1073 (1997).

- "Angular Distribution Study of the ${ }^{29} \mathrm{Si}(\mathrm{p}, \gamma)$ Reaction," C. A. Grossmann, L. K. McLean, G. E. Mitchell, E. F. Moore, J. D. Shriner, E. G. Bilpuch, C. R. Westerfeldt, J. F. Shriner, Jr., and D. C. Powell B.A.P.S. 42, 1787 (1997).

- "Angular Distribution Study of the ${ }^{29} \mathrm{Si}(\mathrm{p}, \gamma)$ Reaction," C. A. Grossmann, W. C. Beal, L. K. McLean, G. E. Mitchell, C. R. Westerfeldt, and J. F. Shriner, Jr., B.A.P.S. 43, 1561 (1998).

- "Parity Violation in an $\mathrm{A} \approx 30$ Compound Nucleus," L. K. Warman, J. F. Shriner, Jr., B. E. Crawford, G. E. Mitchell, C. A. Grossmann, N. R. Roberson, and W. S. Wilburn, B.A.P.S. 44, 988 (1999).

- "Level Statistics for States in ${ }^{30}$ P" C. A. Grossmann, W. C. Beal, L. K. McLean, G. E. Mitchell, C. R. Westerfeldt, J. F. Shriner, Jr., 1999 APS Division of Nuclear Physics Meeting, Abstract CE.09.

- "Reduced Transition Probabilities in ${ }^{30} \mathrm{P}, "$ J. F. Shriner, Jr., C. A. Grossmann, and G. E. Mitchell, 2000 APS April Meeting, Abstract B14.003.

- "Effects of Isospin on Transition Strength Distributions in ${ }^{26} \mathrm{Al}$," J. F. Shriner, Jr., G. E. Mitchell, and B. A. Brown, 2000 SESAPS Meeting, Abstract DA.006.

- "Broken Isospin Symmetry in the Shell Model," J. F. Shriner, Jr., G. E. Mitchell, and B. A. Brown, 2001 SESAPS Meeting, Abstract BD.011.

- "A High-resolution Study of the ${ }^{52} \mathrm{Cr}\left(\mathrm{p}, \mathrm{p}_{0}\right)$ and ${ }^{52} \mathrm{Cr}\left(\mathrm{p}, \mathrm{p}_{1}\right)$ Reactions," E. D. Lake, D. R. Stevens, J. F. Shriner, Jr., L. K. McLean, and G. E. Mitchell, 2003 APS Division of Nuclear Physics Meeting, Abstract 8P.012. 
- "Level Densities in ${ }^{53}$ Mn," D. R. Stevens, E. D. Lake, J. F. Shriner, Jr., L. K. McLean, G. E. Mitchell, 2003 APS Division of Nuclear Physics Meeting, Abstract 8P.050.

- "A High-resolution Study of the ${ }^{52} \mathrm{Cr}\left(\mathrm{p}, \mathrm{p}_{0}\right)$ and ${ }^{52} \mathrm{Cr}\left(\mathrm{p}, \mathrm{p}_{1}\right)$ Reactions," L. K. McLean, W. C. Beal, S. J. Lokitz, D. B. McDevitt, G. E. Mitchell, and J. F. Shriner, Jr., 2003 SESAPS Meeting, Abstract GB.005.

- "A High-resolution Study of the ${ }^{50} \mathrm{Cr}\left(\mathrm{p}, \mathrm{p}_{0}\right)$ and ${ }^{50} \mathrm{Cr}\left(\mathrm{p}, \mathrm{p}_{1}\right)$ Reactions," W. C. Beal, S. J. Lokitz, L. K. McLean, D. B. McDevitt, G. E. Mitchell, and J. F. Shriner, Jr., 2003 SESAPS Meeting, Abstract GB.006.

- "A High-resolution Study of the ${ }^{44} \mathrm{Ca}\left(\mathrm{p}, \mathrm{p}_{0}\right),{ }^{44} \mathrm{Ca}\left(\mathrm{p}, \mathrm{p}_{1}\right)$, and ${ }^{44} \mathrm{Ca}\left(\mathrm{p}, \mathrm{p}_{2}\right)$ Reactions," S. J. Lokitz, W. C. Beal, L. K. McLean, D. B. McDevitt, G. E. Mitchell, and J. F. Shriner, Jr., 2003 SESAPS Meeting, Abstract GB.007.

- "Radiative Capture on ${ }^{48} \mathrm{Ti}, "$ D. B. McDevitt, W. C. Beal, S. J. Lokitz, L. K. McLean, G. E. Mitchell, and J. F. Shriner, Jr., 2003 SESAPS Meeting, Abstract GB.008.

- "Correcting Level Density Measurements for the Effects of Spurious Levels," Jason Knight and J. F. Shriner, Jr., 2004 APS Division of Nuclear Physics Meeting, Abstract CK.033.

- "A High-resolution Study of the p $+{ }^{50} \mathrm{Cr}$ Reaction," B. A. Schwer, E. D. Lake, J. F. Shriner, Jr., D. R. Stevens, L. K. McLean, and G. E. Mitchell, 2004 APS Division of Nuclear Physics Meeting, Abstract CK.066.

- "A High-resolution Study of the p $+{ }^{44}$ Ca Reaction", J. F. Shriner, Jr., S. J. Lokitz, and G. E. Mitchell, 2004 SESAPS Meeting, Abstract HB.006.

- "Measurement of ${ }^{7} \mathrm{Be}+\mathrm{p}$ elastic and inelastic scattering," R. J. Livesay, D. W. Bardayan, J. C. Blackmon, K. Y. Chae, A. E. Champagne, C. Deibel, R. P. Fitzgerald, U. Greife, K. L. Jones, R. L. Kozub, Z. Ma, C. D. Nesaraja, S. D. Pain, F. Sarazin, J. F. Shriner, Jr., D. W. Stracener, M. S. Smith, J. S. Smith, D. W. Visser, C. Wrede, and M. S. Johnson, 2006 APS Division of Nuclear Physics Meeting, Abstract CE.00001.

- "The ${ }^{17} \mathrm{O}(\mathrm{p}, \alpha){ }^{14} \mathrm{~N}$ reaction measured using a novel technique," B. H. Moazen, J. C. Blackmon, D. W. Bardayan, K. Y. Chae, K. Chipps, C. P. Domizioli, R. Fitzgerald, U. Greife, K. L. Jones, R. L. Kozub, R. J. Livesay, C. D. Nesaraja, S. D. Pain, J. F. Shriner, Jr., M. S. Smith, and J. S. Thomas, 2006 APS Division of Nuclear Physics Meeting, Abstract CE.00008.

- "First Experimental Constraints on the Interference of $3 / 2^{+}$Resonances in the ${ }^{18} \mathrm{~F}(\mathrm{p}, \alpha){ }^{15} \mathrm{O}$ Reaction," K. Y. Chae, D. W. Bardayan, J. C.Blackmon, M. S. Smith, M. W. Guidry, C. D. Nesaraja, D. Gregory, R. L. Kozub, S. Paulauskas, J. F. Shriner, Jr., N. Smith, M. S. Johnson, R. J. Livesay, M. Porter-Peden, Z. Ma, S. D. Pain, and J. S. Thomas, 2006 APS Division of Nuclear Physics Meeting, Abstract CE.00011.

- "Statistical Analysis of Nucleon Resonances: Updating the Nuclear Data Ensemble," D. J. Sissom, J. F. Shriner, Jr., and G. E. Mitchell, 2006 APS Division of Nuclear Physics Meeting, Abstract 3A.00079.

- "The Level Structure of ${ }^{19} \mathrm{Ne}$ via Measurement of the ${ }^{2} \mathrm{H}\left({ }^{18} \mathrm{~F}, \alpha+{ }^{15} \mathrm{O}\right) \mathrm{n}$ Reaction," A. S. Adekola, C. R. Brune, Z. Heinen, M. J. Hornish, T. N. Massey, A. V. Voinov, D. W. Bardayan, J. C. Blackmon, C. D. Nesaraja, M. S. Smith, A. Chae, C. Domizioli, Z. Ma, B. Moazen, A. E. Champagne, D. W. Visser, U. Greife, R. Livesay, M. Porter-Peden, M. Johnson, K. L. Jones, S. D. Pain, J. S. Thomas, R. L. Kozub, J. F. Shriner, and N. D. Smith, 2007 APS April Meeting, Abstract Y15.00004. 
- "The ${ }^{130} \mathrm{Sn}(\mathrm{d}, \mathrm{p}){ }^{131} \mathrm{Sn}$ Reaction in Inverse Kinematics," R. L. Kozub, J. F. Shriner, Jr., A. Adekola, D. W. Bardayan, J. C. Blackmon, F. Liang, C. D. Nesaraja, D. Shapira, M. S. Smith, K. Y. Chae, K. L. Jones, Z. Ma, B. H. Moazen, K. Chipps, U. Greife, L. Erikson, J. A. Cizewski, R. Hatarik, S. D. Pain, C. Matei, W. Krolas, and T.P. Swan, 2007 APS April Meeting, Abstract Y15.00005.

- "Measurement of the ${ }^{134} \mathrm{Te}(\mathrm{d}, \mathrm{p})^{135} \mathrm{Te}$ reaction in inverse kinematics," S. D. Pain, J. A. Cizewski, R. Hatarik, P. D. O'Malley, T. P. Swan, D. W. Bardayan, J. C. Blackmon, F. Liang, C. D. Nesaraja, D. Shapira, M. S. Smith, K. Y. Chae, K. L. Jones, B. H. Moazen, R. L. Kozub, J. F. Shriner, Jr., C. Matei, K. Chipps, and R. J. Livesay, 2007 APS April Meeting, Abstract Y15.00006.

- "The ${ }^{17} \mathrm{O}(\mathrm{p}, \alpha){ }^{14} \mathrm{~N}$ Reaction Measured using a Novel Technique," B. H. Moazen, J. C. Blackmon, D. W. Bardayan, K. Y. Chae, K. Chipps, C. P. Domizioli, R. Fitzgerald, U. Greife, W. R. Hix, K. L. Jones, R. L. Kozub, E. J. Lingerfelt, R. J. Livesay, C. D. Nesaraja, S. D. Pain, L. F. Roberts, J. F. Shriner, Jr., M. S. Smith, and J. S. Thomas, 2007 APS Division of Nuclear Physics Meeting, Abstract BC.00004.

- "The Single-particle States in ${ }^{133} \mathrm{Sn}$ Studied through the ${ }^{132} \mathrm{Sn}(\mathrm{d}, \mathrm{p})$ Reaction," Kate Jones, Jolie Cizewski, and the ORRUBA/RIBENS collaboration, 2007 APS Division of Nuclear Physics Meeting, Abstract CE.00006.

- "Measurement of the ${ }^{134} \mathrm{Te}(\mathrm{d}, \mathrm{p})$ Reaction in Inverse Kinematics," Steven Pain and the ORRUBA/RIBENS collaboration, 2007 APS Division of Nuclear Physics Meeting, Abstract CE.00009.

- "Tests of Spurious Levels for Neutron or Proton Resonance Data," R. C. Roller and J. F. Shriner, Jr., 2007 APS Division of Nuclear Physics Meeting, Abstract DA.00066.

- "Statistical Analysis of Proton and Neutron Resonance Data," D. J. Sissom, J. F. Shriner, Jr., and G. E. Mitchell, 2007 APS Division of Nuclear Physics Meeting, Abstract DA.00075.

- "Structure of ${ }^{8} \mathrm{~B}$ through ${ }^{7} \mathrm{Be}+\mathrm{p}$ Scattering," J. C. Blackmon, R. J. Livesay, U. Greife, D. W. Bardayan, K. Y. Chae, A. E. Champagne, C. Diebell, R. Fitzgerald, M. S. Johnson, K. L. Jones, R. L. Kozub, Z. Ma, C. D. Nesaraja, S. D. Pain, F. Sarazin, J. F. Shriner, Jr., D. W. Stracener, M. S. Smith, J. S. Thomas, D. W. Visser, and C. Wrede, 2007 APS Division of Nuclear Physics Meeting, Abstract HD.00007.

- "Single Particle States in ${ }^{131}$ Sn and the r-process," R. L. Kozub, J. F. Shriner, Jr., A. Adekola, D. W. Bardayan, J. C. Blackmon, F. Liang, C. D. Nesaraja, D. Shapira, M. S. Smith, K. Y. Chae, K. L. Jones, Z. Ma, B. H. Moazen, K. Chipps, L. Erikson, J A. Cizewski, R. Hatarik, S. D. Pain, C. Matei, W. Krolas, and T. P. Swan, 2007 APS Division of Nuclear Physics Meeting, Abstract HD.00010.

- "Effects on ${ }^{18} \mathrm{~F}$ Production in Novae from Changes in the ${ }^{17} \mathrm{O}(\mathrm{p}, \alpha){ }^{14} \mathrm{~N}$ Rate," B. H. Moazen, J. C. Blackmon, D. W. Bardayan, K. Y Chae, K. Chipps, C. P. Domizioli, R. Fitzgerald, U. Greife, W. R. Hix, K. L. Jones, R. L. Kozub, E. J. Lingerfelt, R. J. Livesay, C. D. Nesaraja, S. D. Pain, L. F. Roberts, J. F. Shriner, Jr., M. S. Smith, and J. S. Thomas, 2008 APS April Meeting, Abstract H15,00003.

- "First Direct Measurement of the ${ }^{17} \mathrm{~F}(\mathrm{p}, \gamma){ }^{18} \mathrm{Ne}$ Cross Section," K. A. Chipps, U. Greife, D. W. Bardayan, C. D. Nesaraja, S. D. Pain, M. S. Smith, J. C. Blackmon, K. Y. Chae, B. H. Moazen, S. T. Pittman, R. Hatarik, W. A. Peters, R. L. Kozub, J. F. Shriner, and C. Matei, 2008 APS Division of Nuclear Physics Meeting, Abstract CD.00004. 
- "Using $(\mathrm{d}, \mathrm{p} \gamma)$ as a Surrogate for Neutron Capture with ${ }^{75}$ As," W. A. Peters, J. A. Cizewski, R. Hatarik, P. O'Malley, D. J. Vieira, M. Jandel, J. B. Wilhelmy, C. Matei, D. W. Bardayan, M. S. Smith, S. D. Pain, K. L. Jones, B. H. Moazen, K. Y. Chae, R. L. Kozub, J. Shriner, and J. C. Blackmon, 2008 APS Division of Nuclear Physics Meeting, Abstract HB.00007.

- "New Measurements of Spectroscopic Factors for Low-lying ${ }^{16} \mathrm{~N}$ Levels," P. D. O'Malley, J. A. Cizewski, R. Hatarik, S. D. Pain, W. A. Peters, D. W. Bardayan, C. D. Nesaraja, M. S. Smith, J. C. Blackmon, K. L. Jones, S. T. Pittman, K. Y. Chae, S. Paulauskas, B. H. Moazen, R. L. Kozub, J. F. Shriner, Jr., C. Matei, and K. A. Chipps, 2008 APS Division of Nuclear Physics Meeting, Abstract MG.00004.

- "Measurement of Low Energy Resonances in ${ }^{31} \mathrm{P}(\mathrm{p}, \alpha){ }^{28} \mathrm{Si}$," B. H. Moazen, C. Matei, D. W. Bardayan, J. C. Blackmon, K. Y. Chae, K. A. Chipps, R. Hatarik, K. L. Grzywacz, R. W. Kapler, R. L. Kozub, M. Matos, C. D. Nesaraja, S. D. Pain, T. Pelham, W. A. Peters, S. T .Pittman, J. F. Shriner, Jr, and M. S. Smith, 2008 APS Division of Nuclear Physics Meeting, Abstract MG.00009.

- "Single-particle structure of ${ }^{133} \mathrm{Sn}$ explored through the ${ }^{132} \mathrm{Sn}(\mathrm{d}, \mathrm{p})$ reaction in inverse kinematics," K. L. Jones, R. L. Kozub, S. D. Pain, A. S. Adekola, D. W. Bardayan, J. C. Blackmon, K. Y. Chae, K. A. Chipps, J. A. Cizewski, L. Erikson, C. Harlin, R. Hatarik, R. Kapler, J. F. Liang, R. J. Livesay, Z. Ma, B. H. Moazen, C. D. Nesaraja, N. P. Patterson, D. Shapira, J. F. Shriner, Jr., M. S. Smith, T. P. Swan, and J. S. Thomas, 2009 APS April Meeting, Abstract L10.00006. 


\section{Appendix II}

Undergraduate Research Assistants Employed with DOE Support since 1996

\begin{tabular}{|c|c|c|}
\hline Student & $\begin{array}{l}\text { Years } \\
\text { Employed }\end{array}$ & Last Known Status \\
\hline M. A. Blackston & 1999-2001 & $\begin{array}{l}\text { B. S., Physics, TTU, } 2000 \\
\text { Ph.D., Nuclear Physics, Duke University, } 2007 \\
\text { Employed at Oak Ridge National Laboratory }\end{array}$ \\
\hline J. M. Cox & 1996-97 & $\begin{array}{l}\text { B. S., Physics/Chemistry, TTU, } 1999 \\
\text { Ph.D., Nuclear Physics, University of Notre Dame, } 2007\end{array}$ \\
\hline C. R. Downum & 2002 & $\begin{array}{l}\text { B. S., Physics, TTU, } 2004 \\
\text { Graduate Student in Physics, Oxford }\end{array}$ \\
\hline L. M. Fittje & 1995-96 & $\begin{array}{l}\text { B. S., Electrical \& Computer Engineering, TTU, } 1999 \\
\text { Systems Engineer, Battelle Energy Alliance }\end{array}$ \\
\hline D. R. Gregory & 2005 & $\begin{array}{l}\text { B. S., Physics, TTU, } 2007 \\
\text { Graduate Student in Education, TTU }\end{array}$ \\
\hline M. W. Heims & 2002 & Left school \\
\hline M. F. Kidd & 2001 & $\begin{array}{l}\text { B. S., Physics, TTU, } 2004 \\
\text { Graduate Student in Nuclear Physics, Duke University }\end{array}$ \\
\hline J. D. Knight & 2004 & $\begin{array}{l}\text { B. S., Physics, TTU, } 2006 \\
\text { M. S., Mathematics, TTU, } 2009\end{array}$ \\
\hline J. G. Knight & 1997 & B. S., Mechanical Engineering, TTU, 2001 \\
\hline E. D. Lake & 2003 & B. S., Physics/Mechanical Engineering, TTU, 2005 \\
\hline P. D. O'Malley & 2006 & $\begin{array}{l}\text { B. S., Physics, TTU, } 2006 \\
\text { Graduate Student in Nuclear Physics, Rutgers University }\end{array}$ \\
\hline S. V. Paulauskas & 2005 & $\begin{array}{l}\text { B. S., Physics, TTU, } 2007 \\
\text { Graduate Study in Nuclear Physics, University of Tennessee }\end{array}$ \\
\hline R. C. Roller & 2007 & B. S., Physics, TTU, 2008 \\
\hline B. A. Schwer & 2004 & $\begin{array}{l}\text { B. S., Physics, TTU, } 2006 \\
\text { M.S., Mathematics, TTU, } 2008\end{array}$ \\
\hline D. J. Sissom & $2006-07$ & $\begin{array}{l}\text { B. S., Physics, TTU, } 2009 \\
\text { Graduate Student in Physics, Vanderbilt University }\end{array}$ \\
\hline D. R. Stevens & 2003 & $\begin{array}{l}\text { B. S., Physics, TTU, } 2004 \\
\text { Graduate Student in Physics, North Carolina State University }\end{array}$ \\
\hline
\end{tabular}

